\title{
A retrosynthetic co-templating method for the preparation of silicoaluminophosphate molecular sieves
}

Alessandro Turrina, ${ }^{1,2^{*}}$ Raquel Garcia, ${ }^{2}$ Paul A. Cox ${ }^{3}$ John L. Casci ${ }^{2}$ and Paul A. Wright ${ }^{1 *}$

${ }^{1}$ EaStCHEM School of Chemistry, University of St Andrews, Purdie Building, North Haugh, St Andrews, KY169ST, UK.

${ }^{2}$ Johnson Matthey, Chilton PO Box 1, Belasis Avenue, Billingham, TS23 1LB, UK.

${ }^{3}$ School of Pharmaceutical and Biomedical Sciences, University of Portsmouth, St. Michael's Building, White Swan Road, Portsmouth, PO1 2DT, UK.

\begin{abstract}
A retrosynthetic method has been developed to design the synthesis of target zeotypes whose frameworks belong to the ABC-6 structural family and which contain gme cages. This permits the preparation of silicoaluminophosphate versions of AFX (SAPO-56), SFW (STA18) and GME (STA-19) topology types. The method makes simultaneous use of two organic structure directing agents (SDAs) to promote the formation of structural features such as cages or channels of the target framework. Computational modelling was used to identify SDAs for gme and other cages or channels in the target structures. The trimethylammonium cation was found to be the most favourable SDA for the gme cage while bisdiazabicyclooctane (DABCO) alkane cations and quaternary ammonium oligomers of DABCO with connecting polymethylene chain lengths of 4 to 8 methylene units acted as
\end{abstract}


templates for the additional cages or channels, respectively. The incorporation of each of the co-SDAs in the as-prepared materials was confirmed by chemical analysis, ${ }^{13} \mathrm{C}$ MAS NMR and Rietveld refinement combined with computational modeling. Calcination of the SAPO56, STA-18 and some of the STA-19 materials gives microporous, fully tetrahedrallycoordinated framework solids with AFX, SFW and GME topologies: other STA-19 samples convert topotactically to SAPO-5. These results show that SAPOs in the ABC-6 family can be prepared via a targeted co-templating approach.

\section{Introduction}

Aluminosilicate zeolites and their aluminophosphate zeotype analogues find increasing use in a range of adsorption and catalytic processes..$^{1-4}$ In each case the choice of material is limited to the 50 or so known synthetically-accessible structure types ${ }^{5}$ that can be prepared in stable and active forms. However, it has been established that there are millions of hypothetical zeolite structure types, ${ }^{6-8}$ many as energetically feasible as those observed experimentally, which have not yet been synthesised. Many of these would be expected to have outstanding properties in shape selective catalysis, and recent in silico assessment of their properties has suggested some of these could be ideal for target applications. ${ }^{8,9}$

There has therefore been a tremendous synthetic effort towards the direct synthesis of novel structures. The most successful approach to new structures, particularly for materials with relatively low framework charge densities, is to use organic structure directing agents, OSDAs, which are typically alkylammonium cations or amines. ${ }^{10-17}$ The short-range nonbonding interaction energies of these with the oxygen atoms of the framework are found to be crucial in determining which phase crystallises. ${ }^{18-21}$ 
In most cases, new zeolites have resulted from exploratory crystallisation in the presence of a wide range of OSDAs which are either available commercially or prepared by customised syntheses, with screening of conditions and inorganic gel composition for each OSDA tried. However, there have also been successful attempts to synthesise specified zeolite structures through targeted template design, making use of molecular modelling to design OSDAs that have highly favourable interaction energies with a part of the zeolite, usually a cage. The first of these methods used the ZEBEDDE code to predict templates for the chabazite zeotype, ${ }^{22,23}$ whereas the most recent, that of Deem, ${ }^{24}$ introduces into the program elements that take into account the practicality of synthesis of the prospective template. The last method has successfully predicted templates for the RTH, AEI and STW silicate frameworks. ${ }^{25-27}$

However, many zeolite structures have more than one type of cage, or intra framework void, and each must be filled by template or solvent upon crystallisation to stabilise the open structure. Where such structures have successfully been templated by a single OSDA (e.g. DAF- $1^{28}$, TNU- $9^{29}$ ) the organic fits very well to one (or more) cage type while the remainder take up water or poorly fitting organic species via 'void filling'. Such inefficient filling of pores leaves these crystallising systems vulnerable to competing crystallisations, especially from phases in which the OSDA fills all available spaces. The approach of co-templating, in which more than one template is chosen to fit closely to the different cage or channel types, is therefore energetically attractive, with the proviso that both templates should be incorporated simultaneously, and so should have similar templating tendencies. Where such conditions are not met, competitive pathways involving only one of the OSDAs, or giving more than one phase with the different templates, might be expected to dominate.

Nevertheless, we have shown that true co-templating, where each OSDA is a close fit to one of the two cage types in the target structure, can be used successfully to prepare silico- 
aluminophosphate (SAPO) frameworks that had not been accessible via other routes. The SAV structure type, for example, is built from the stacking of double six-membered rings (D6Rs) in such a way that there are two cage types, one considerably larger than the other. To

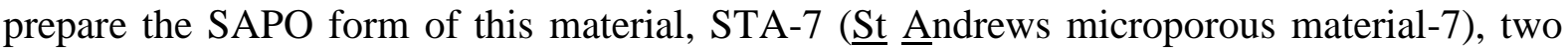
different templates are required, tetraethylammonium cations $\left(\mathrm{TEA}^{+}\right)$and cyclam, which fit its smaller and larger cages, respectively. ${ }^{30}$ This synthesis has been developed further to include a copper cyclam complex, giving a direct route to a precursor for a catalyst for the selective catalytic reduction (SCR) of $\mathrm{NO}$ with $\mathrm{NH}_{3} \cdot{ }^{31}$ Similarly, we prepared the SAPO form of the KFI framework using a co-templating approach. ${ }^{30}$ It is worth noting here that an analogous 'co-templating' effect occurs in the stabilisation of gas hydrates with two types of cavities by alkane molecules of different sizes. ${ }^{32}$

Building on these successful syntheses, we reasoned that it should be possible to identify families of structures containing more than one type of cage or channel and to prepare them by a form of retrosynthetic analysis. Here we define retrosynthetic analysis as an approach to the decomposition of a target structure into simpler structural components for which synthetic routes can be established computationally, and then combined to give the target. Our aim was to examine the cages or channels present in the structure and to choose OSDAs for each of them, making use of molecular modelling to suggest candidate molecules. In this way, the most efficient filling of pore space might be achieved, improving the probability that the structure types could form. The SAPO ABC-6 structure family was chosen for investigation, because template control of crystallisation is known to give three-dimensionally connected small pore zeotypes of interest in $\mathrm{SCR}^{3}$ and methanol-to-olefin ${ }^{4}$ catalysis. Examples of SAPOs of this type, where the cages are connected via openings delimited by rings containing eight tetrahedrally-coordinated cations (8Rs), include SAPO-17 (ERI), -34 (CHA), -35 (LEV), -56 (AFX) and STA-2 (SAT), each prepared using a single OSDA. 
The ABC-6 structural family is made up of members built from layers of 6 Rs with different stacking arrangements, themselves linked by $4 \mathrm{Rs} .{ }^{33}$ The $6 \mathrm{R}$ units can be centred on three different $\mathrm{x}$, y positions in the hexagonal $a b$-plane: A $(0,0), \mathrm{B}(2 / 3,1 / 3)$ and $\mathrm{C}(1 / 3,2 / 3)$. Li et al have recently enumerated the 84,292 hypothetical structures in this family with repeat units up to 16 layers and identified by modelling the 1,127 of these that are most likely to be feasible. ${ }^{8}$ We chose to investigate a subset of ABC- 6 structures that contain gme cages as one of two types of void (cages, channels) present, and limited our approach to targeting structure types comprising only D6R units (and not single 6Rs). This choice was made because the gme cage looked like a suitable target to template, and because our previous work on families of materials built only from D6Rs had shown structure direction via OSDAs to be feasible in this system. $^{30,31,34}$ The method should also be applicable to structures containing S6R building units as well as D6Rs, but these were not targeted in the current work.

Our first step in selecting D6R target structures in the ABC-6 system for synthesis as SAPOs was to see which frameworks that contained gme cages (sequence AABBAA) had already been crystallised either as SAPOs or aluminosilicate zeolites. These included GME, SAPO56 (AFX), SSZ-52 (SFW) and AlPO-52 (AFT). Other known structure types do possess gme cages, but are either not in the ABC-6 system (i.e. EON, LTF and MAZ) or also include single 6Rs (i.e. AVL, EAB and OFF), and so were not chosen as targets.

The first target was SAPO-56 (AFX), stacking sequence AABBAACC(A). This possesses gme cages and also long aft cages (Figure 1). Its synthesis has been reported previously, both using a single OSDA, N,N,N',N'-tetra-methyl-hexane-1,6-diamine ${ }^{35}$ or $\alpha, \omega$-bis(Nmethylpyrrolidinium)alkane ${ }^{36}$ in the aft cages, or, since our work was completed, from an aminothermal synthesis containing triethylamine and trimethylamine in the synthesis ${ }^{37}$ (discussed in more detail below). It was therefore chosen as a model structure to understand co-templating in this system. The second target was SFW, recently reported as an alumino- 
silicate $^{38}$, with an idealised stacking sequence AABBAABBCCBBCCAACC(A), although the reported material shows a considerable concentration of stacking faults. As well as gme cages, the structure also contains a longer $s f w$ cage (Figure 1) that appeared amenable to OSDA modelling studies. The third target was gmelinite itself (GME), with a stacking sequence $\mathrm{BBCC}(\mathrm{B})$ according to the above nomenclature, which is equivalent to $\mathrm{AABB}(\mathrm{A})$. The structure contains gme cages and also 12R channels (Figure 1), and so provided a different challenge for the retrosynthetic approach. Notably, unfaulted aluminosilicate gmelinite has previously been prepared by adding cationic polymers to the synthesis gel. ${ }^{39}$ Following a co-templating synthetic approach, and combining modelling, synthesis and characterisation, we have successfully prepared three targeted SAPOs that contain more than one intra-framework type of cage or channel. 

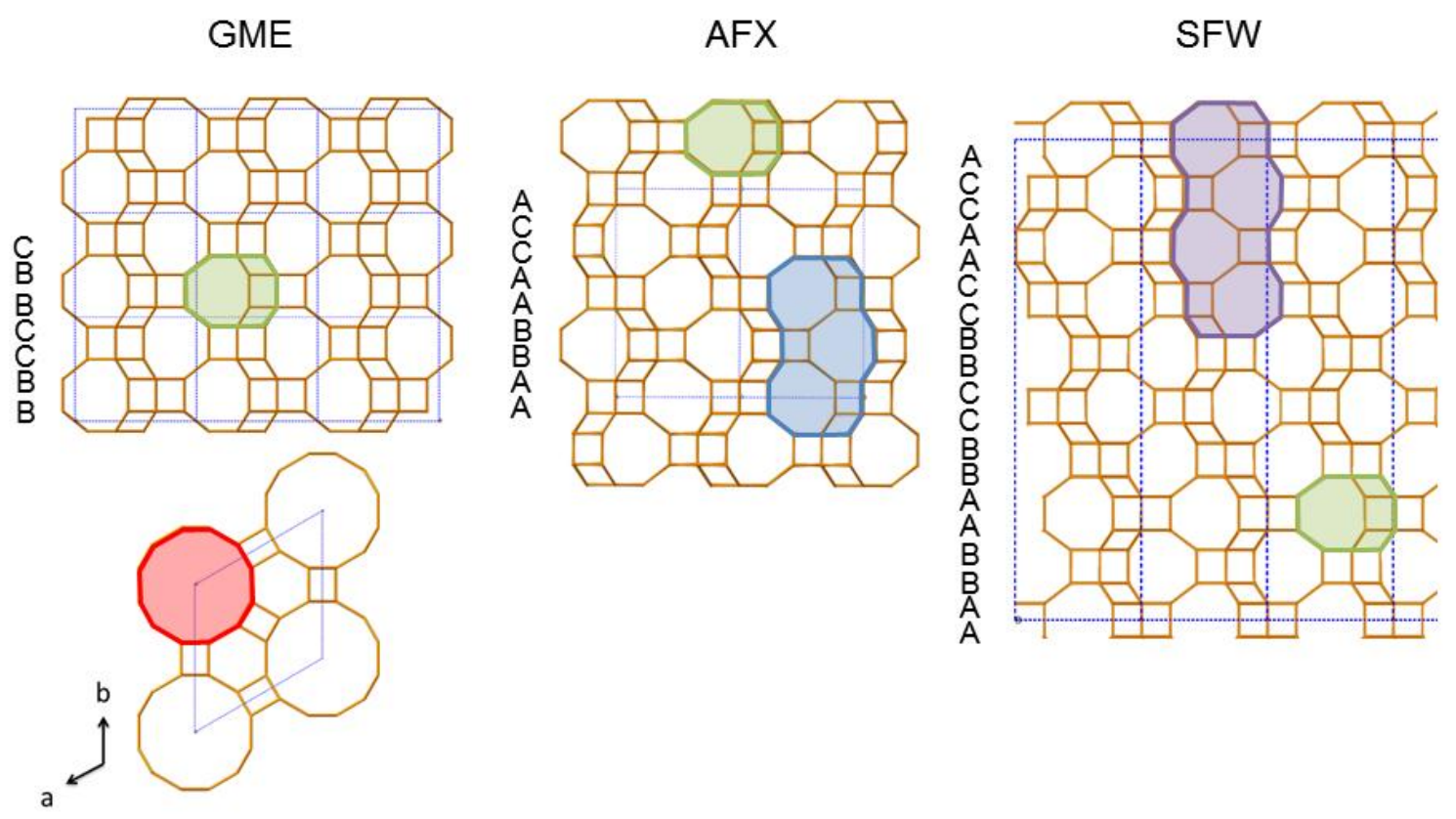

Figure 1. GME, AFX and SFW framework structures showing the different types of cages and channel (green: gme; blue: aft; violet: $s f w$; red: 12R channel). Oxygen atoms are omitted for clarity. The stacking sequences of the $6 \mathrm{R}$ layers are given on the left.

\section{Experimental details}

\subsection{Synthesis and preparation}

The synthesis and characterisation of the organic compounds diDABCO-C5, diDABCO-C6, diDABCO-C7, diDABCO-C8 and the oligomers [DABCO-C5 $]_{3}$, and [DABCO-C6 $]_{3}$ (where the subscript 3 indicates the average number of repeating units) used as SDAs are reported in the Supporting Information. The diDABCO-C4 and $[\mathrm{DABCO}-\mathrm{C} 6]_{2},[\mathrm{DABCO}-\mathrm{C} 6]_{5}$ and $[\mathrm{DABCO}-\mathrm{C} 6]_{7}$ oligomers were purchased from Valiant and Alfa Aesar, respectively. An example of each of the types of DABCO SDAs is shown in Scheme 1. The synthesis gels were prepared by mixing orthophosphoric acid ( 85 wt. \% in $\mathrm{H}_{2} \mathrm{O}, \mathrm{BDH}$ ) with fumed silica (particle size $0.007 \mu \mathrm{m}$, Aldrich) and aluminium hydroxide (Aldrich) in water and stirred at 
room temperature. After 30 minutes the selected $\mathrm{DABCO}$ template and trimethylamine (45 wt.\% in $\mathrm{H}_{2} \mathrm{O}$, Aldrich) were added. If necessary, tetrabutylammonium hydroxide, TBAOH, (40 wt.\% in $\mathrm{H}_{2} \mathrm{O}$, Aldrich) was used to adjust the gel $\mathrm{pH}$ to 7 . In order to favour the crystallisation of the desired phase, seeds of as-prepared SAPO AFX (2.0-4.0 \% wt. with respect to the $\mathrm{SiO}_{2}$ content) were added. After being stirred for at least 2 hours at room temperature, the final synthesis mixture was charged into a Teflon-lined 30-mL autoclave and heated at 160 or $190{ }^{\circ} \mathrm{C}$ for between 4 and 7 days. The solid product was recovered by filtration, washed repeatedly with water, and then dried overnight in air at $80{ }^{\circ} \mathrm{C}$ for 12 hours. Overall gel compositions which gave the desired materials as pure phases are reported in Table 1.

Table 1. Gel compositions and hydrothermal synthesis conditions used to prepare pure SAPOs with the AFX, SFW and GME framework topologies.

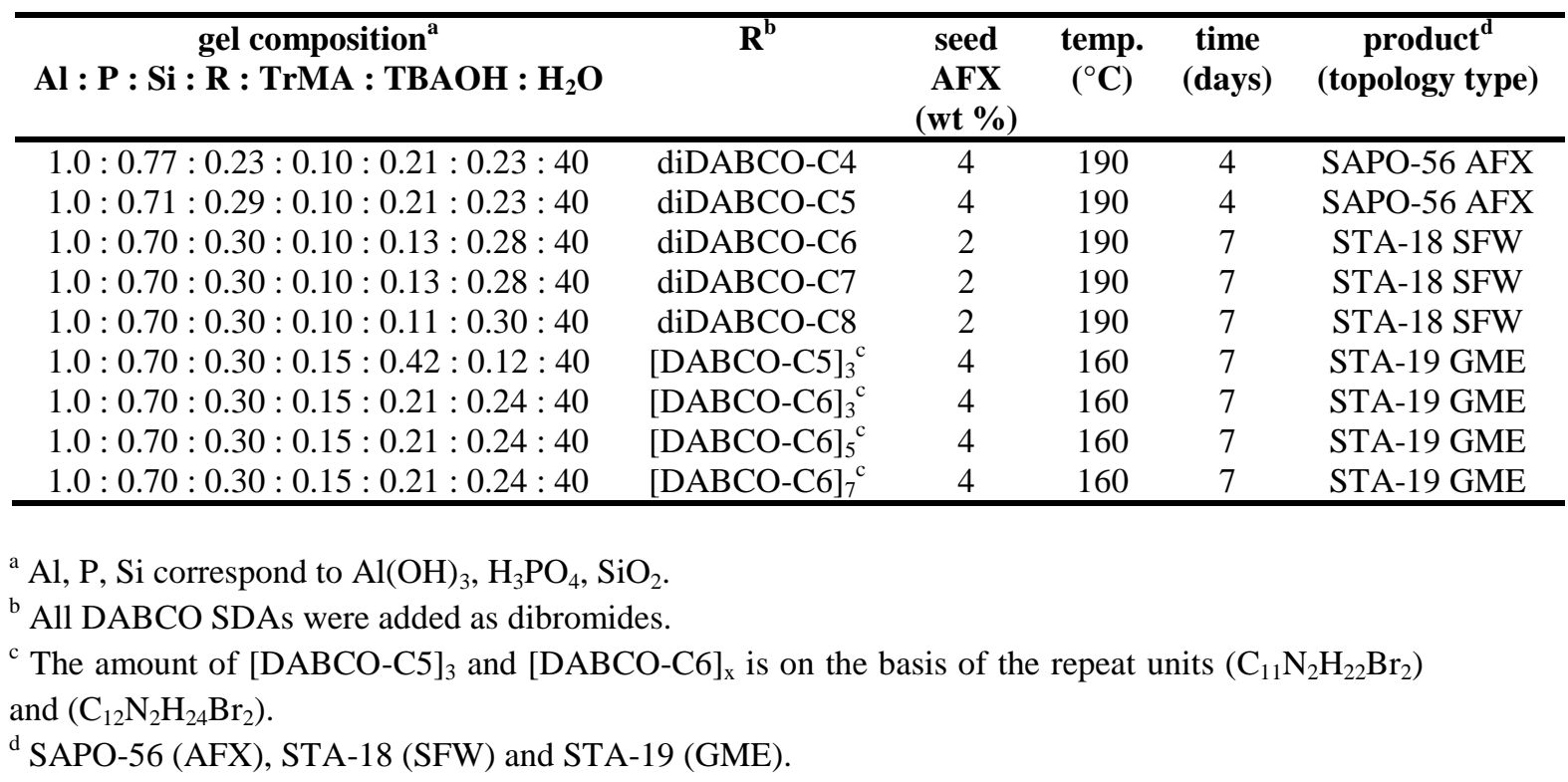



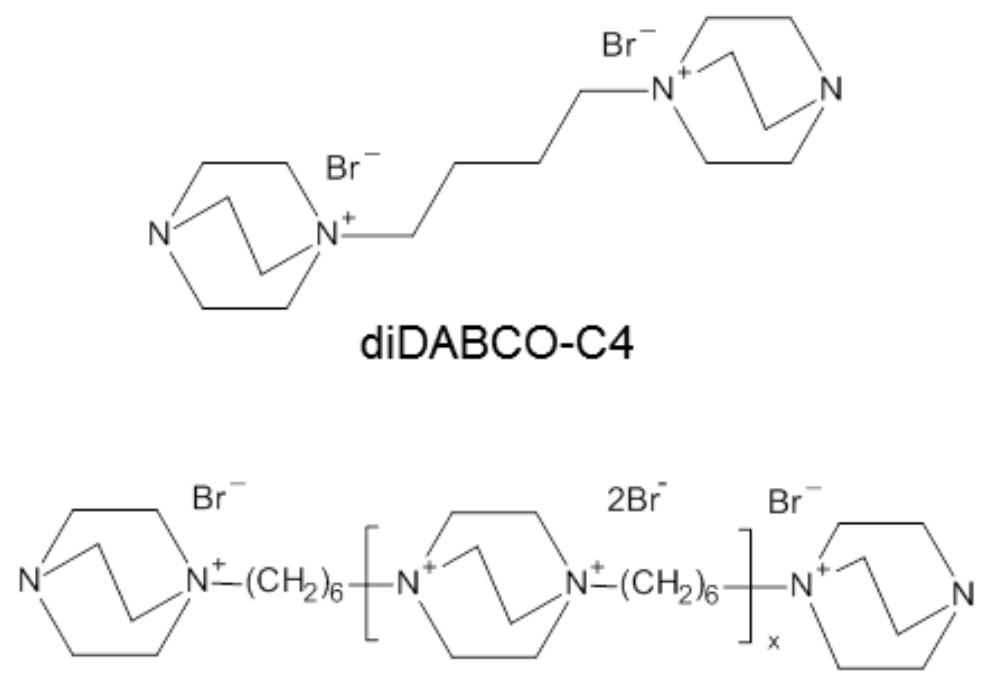

[DABCO-C6 $]_{x}$ oligomer

Scheme 1. SDAs based on diquaternary salts of DABCO and quaternary ammonium oligomers of DABCO used for the synthesis of SAPO with the framework topologies AFX, SFW and GME.

\subsection{Molecular Modelling}

In order to find OSDAs suitable for gme, aft and $s f w$ cages, molecular modelling studies were performed using the Forcite module within the program Materials Studio version $6.1 .^{40}$ The small quaternary ammonium cations were energy-minimised within the appropriate isolated cage rather than within the entire framework. The Universal Force Field was used and the negative charges were spread across all the atoms in the framework so that a neutral simulation box was maintained upon introduction of small quaternary ammonium cations (or protonated amines) or diDABCOs with $\mathrm{a}+1$ and +2 charge, respectively. The cages were simulated using an aluminium phosphate model (Al:P of 1:1) and the outside $\mathrm{O}$ atoms of these cages were terminated with hydrogen atoms and held fixed throughout the simulations. Energy minimisation was performed following a simulated annealing protocol that ran for 100,000 steps at temperatures of $476.85{ }^{\circ} \mathrm{C}, 226{ }^{\circ} \mathrm{C}, 26.85^{\circ} \mathrm{C}$ and $-173.15^{\circ} \mathrm{C}$. The time step 
used was $1 \times 10^{-15} \mathrm{~s}$. Once the simulation was complete, the overall interaction energy and the torsion energy of the SDA were extracted. The latter is the energy difference between the configuration of the SDA in its minimum energy state outside the solid and its adopted configuration within the cages of the aluminophosphate structures. Molecular modelling was also used to simulate the SDAs' positions within the aluminophosphate frameworks for the Rietveld refinement of the as-prepared materials.

\subsection{Characterisation}

For phase identification purposes, X-ray powder diffractograms in the $2 \theta$ range $5-50^{\circ}$ (step size $0.01^{\circ}$, time step ${ }^{-1} 160 \mathrm{~s}, 0.04 \mathrm{rad}$ soller, $45 \mathrm{kV}, 35 \mathrm{~mA}$ ) were recorded on a Panalytical Empyrean automated diffractometer equipped with a X'Celerator detector. The data were collected in Bragg-Brentano geometry, using $\mathrm{Cu} \mathrm{K \alpha} \alpha_{1}(\lambda=1.54056 \AA)$ X-radiation via a primary monochromator. For refinement purposes, samples were loaded in 0.7 or $1.0 \mathrm{~mm}$ quartz-glass capillaries and dehydrated at a temperature of $170-250^{\circ} \mathrm{C}$ under a vacuum of $10^{-}$

${ }^{5}$ mbar for 10 hours before being sealed and mounted on the diffractometer. X-ray powder diffractograms in the $2 \theta$ range $3-80^{\circ}$ (step size $0.01^{\circ}$, time step ${ }^{-1} 80 \mathrm{~s}, 40 \mathrm{kV}, 35 \mathrm{~mA}$ ) were measured in Debye-Scherrer mode on a Stoe STAD I/P diffractometer with a primary monochromator, using $\mathrm{Cu} \mathrm{K} \alpha_{1}$ X-radiation $(\lambda=1.54056 \AA)$ and equipped with a linear PSD detector. Scanning electron microscopy on samples was carried out with a JEOL JSM 6700F SEM with an Oxford INCA Energy 200 EDX analyser to determine the Si, Al and P content. Thermogravimetric analysis of as-prepared samples was performed on a NETZSCH TG1000M in a dry air flow with a heating range of $5{ }^{\circ} \mathrm{C} \mathrm{min}^{-1}$. Elemental analysis was carried out by Elemental Analysis Service, London Metropolitan University, United Kingdom. Solid-state NMR spectra were collected at room temperature using a Varian VNMRS 400 spectrometer, equipped with a widebore $14.1 \mathrm{~T}$ magnet, yielding Larmor 
frequencies of 104.2 MHz for ${ }^{27} \mathrm{Al}, 161.9 \mathrm{MHz}$ for ${ }^{31} \mathrm{P}, 79.4 \mathrm{MHz}$ for ${ }^{29} \mathrm{Si}, 100.6 \mathrm{MHz}$ for ${ }^{13} \mathrm{C}$ and $40.5 \mathrm{MHz}$ for ${ }^{15} \mathrm{~N}$. As-prepared and calcined samples were dehydrated overnight at 150 ${ }^{\circ} \mathrm{C}$ or $200{ }^{\circ} \mathrm{C}$, respectively, before being packed in $4 \mathrm{~mm} \mathrm{ZrO}_{2}$ rotors and rotated at a rate of 12.8 or $13.5 \mathrm{kHz}$ for ${ }^{27} \mathrm{Al}, 6.8 \mathrm{kHz}$ for ${ }^{31} \mathrm{P},{ }^{29} \mathrm{Si},{ }^{15} \mathrm{~N}$ and $6.0 \mathrm{kHz}$ for ${ }^{13} \mathrm{C}$. Chemical shifts were recorded in ppm relative to $1 \mathrm{M} \mathrm{Al}\left(\mathrm{NO}_{3}\right)_{3}$ (aq) for ${ }^{27} \mathrm{Al}, 85 \% \mathrm{H}_{3} \mathrm{PO}_{4}$ for ${ }^{31} \mathrm{P}$, TMS for ${ }^{29} \mathrm{Si}$, ${ }^{13} \mathrm{C}$ and $\mathrm{CH}_{3} \mathrm{NO}_{2}$ for ${ }^{15} \mathrm{~N} .{ }^{27} \mathrm{Al},{ }^{31} \mathrm{P}$ and ${ }^{29} \mathrm{Si}$ MAS NMR spectra were recorded with a onepulse sequence (direct extinction) at repeat intervals of $10 \mathrm{~ms}$ for ${ }^{27} \mathrm{Al}, 15$ or $20 \mathrm{~ms}$ for ${ }^{31} \mathrm{P}, 30$ ms for ${ }^{29} \mathrm{Si}$ and in a spectral width of $416.7 \mathrm{kHz}$ for ${ }^{27} \mathrm{Al}, 100.0 \mathrm{kHz}$ for ${ }^{31} \mathrm{P}$ and $40.3 \mathrm{kHz}$ for ${ }^{29} \mathrm{Si} .{ }^{13} \mathrm{C}$ and ${ }^{15} \mathrm{~N}$ MAS NMR spectra were recorded with standard cross-polarisation (CP) pulses at repeat interval of $30 \mathrm{~ms}$ and in a spectral width of $40.3 \mathrm{kHz}$ for ${ }^{13} \mathrm{C}$ and $62.5 \mathrm{kHz}$ for ${ }^{15} \mathrm{~N}$. Detemplation of selected samples was performed in a tube furnace at a temperature ranging between $500-600{ }^{\circ} \mathrm{C}$ (reached via a heating ramp of $20^{\circ} \mathrm{C} \min ^{-1}$ ), for 12 hours in a stream of dry oxygen. To establish the porosity of the calcined solids, adsorption isotherms for $\mathrm{N}_{2}$ at $-196.15{ }^{\circ} \mathrm{C}$ have been measured using a Micromeritics Tristar II 3020 apparatus. The samples were activated at $150-180{ }^{\circ} \mathrm{C}$ in order to remove the physisorbed water.

\subsection{Crystallography: Rietveld refinement}

Rietveld refinement of the structures of selected dehydrated as-prepared and calcined materials was carried out using the GSAS suite of programs and the EXPGUI graphical interface. ${ }^{41}$ The energy-minimised structural models of SAPO-56 and SAPO STA-18 (SFW) were used as starting models for the relevant refinements. The silicate structure reported in the IZA website ${ }^{5}$ was used as a starting model for the refinement of calcined SAPO STA-19 (GME). The space groups were changed from $P 1$ to $P-31 c, P 1$ to $R-3$ and $P 6_{3} / m m c$ to $P-31 c$ for SAPO-56, SAPO STA-18 and SAPO STA-19, respectively, to take symmetry and A1/P ordering into account. The instrumental background was fitted either automatically by using a Chebyschev function or edited manually by choosing the points over the pattern and further 
interpolated using a Chebyschev function. The peak profiles were modelled using a PseudoVoigtian function (type 4). ${ }^{42}$ The framework Al-O, P/Si-O, O-O(Al), and O-O(P/Si) distances were soft constrained to $1.72 \AA(\sigma=0.025 \AA), 1.51 \AA(\sigma=0.025 \AA), 2.82 \AA(\sigma=0.025 \AA)$, and $2.50 \AA$ ( $\sigma=0.025 \AA$ ), respectively, for calcined (framework only) samples. In the case of as-prepared SDA-containing samples, the $\sigma$ values were fixed to $0.01 \AA$ and $0.02 \AA$ for T-O and $\mathrm{O}-\mathrm{O}$ distances, respectively. The isotropic atomic displacement parameters of the atoms were constrained to be the same in groups for the tetrahedral sites ( $\mathrm{Al}, \mathrm{P}, \mathrm{Si}$ ) and $\mathrm{O}$ atoms respectively. For the as-prepared samples the atomic coordinates of the SDA atoms obtained by energy minimisation calculations were not refined because the symmetry of the flexible templates are different from those of the frameworks, leading to diffuse electron density due to the static disorder. Studies have shown that where SDA atom locations have been determined experimentally, they have been closely similar to those predicted by modelling. ${ }^{43}$ An overall isotropic atomic displacement parameter was set to $0.005 \AA^{2}$ for all $\mathrm{C}, \mathrm{N}, \mathrm{H}$ atoms, while the fractional occupancy were constrained in groups for the diDABCO and trimethylamine atoms. During the cycles of refinement only the occupancy of the SDAs atoms was allowed to refine, together. Hydroxyl groups known from the ${ }^{27}$ Al MAS NMR to be coordinated to framework $\mathrm{Al}^{3+}$ cations in all materials have not been taken into account during the Rietveld refinements of as-prepared materials because there was no evidence that they were ordered. Convergence was achieved by refining simultaneously all profile parameters, scale factor, lattice constants, $2 \theta$ zero-point, and atomic positional and atomic displacement parameters for the framework atoms and, for the as-prepared samples, the occupancies of the SDAs atoms. 


\section{Results and Discussion}

\subsection{Templating the gme cage}

Having chosen AFX, SFW and GME as targets, the first step was to perform modelling of the OSDAs most likely to favour the crystallisation of the gme cage through the energetics of their interactions, and to investigate their action in an aluminophosphate-based synthesis. Protonated tertiary amine and quaternary alkyl ammonium compounds were modelled as potential structure-directing agents for the gme cage, because these types of compounds have been found to be highly effective as OSDAs for SAPOs. Here we examined trimethylammonium $\left(\mathrm{HTrMA}^{+}\right)$, tetramethylammonium $\left(\mathrm{TMA}^{+}\right)$ethyldimethylammonium $\left(\mathrm{HEDMA}^{+}\right)$, diethylmethyl-ammonium $\left(\mathrm{HDEMA}^{+}\right)$, diethyldimethylammonium $\left(\mathrm{DEDMA}^{+}\right)$, triethylammonium $\left(\mathrm{HTrEA}^{+}\right)$and triethylmethylammonium $\left(\operatorname{TrEMA}^{+}\right)$. The molecules, together with their acronyms, are shown in Scheme 2. The amines were examined in their protonated form because at the neutral $\mathrm{pH}(6-7)$ used during hydrothermal synthesis the protonated form is stable. ${ }^{44}$

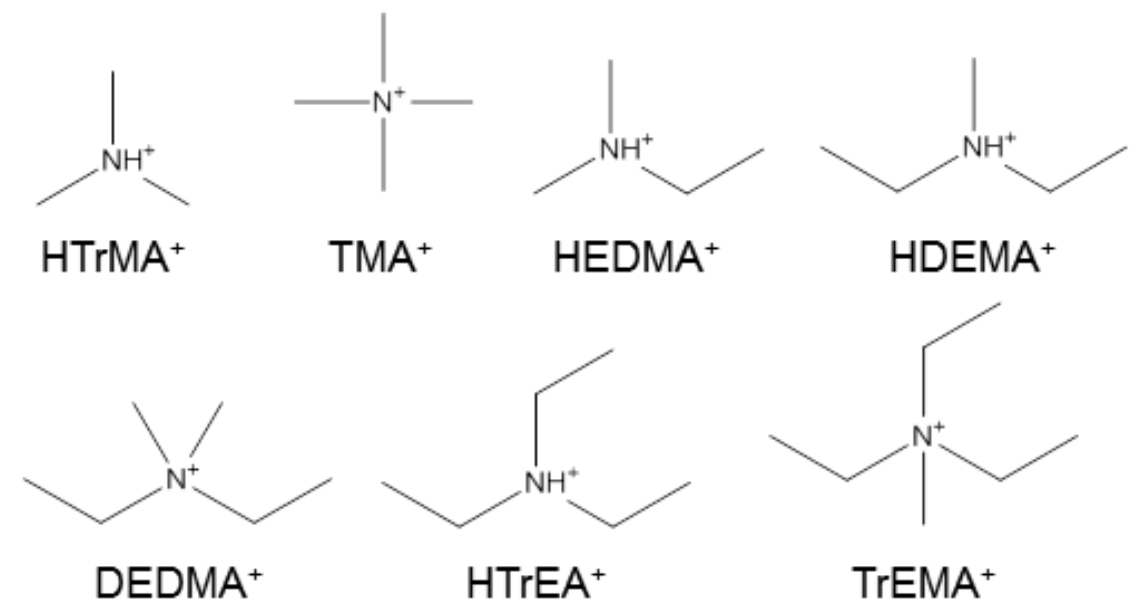

Scheme 2. Protonated tertiary amine and quaternary alkyl ammonium compounds that were modelled within the gme cage. 
As shown by the binding energies in Table 2, the three-fold $\left(\mathrm{HTrMA}^{+}\right)$or pseudo-three-fold molecules $\left(\mathrm{HEDMA}^{+}\right.$and $\mathrm{HDEMA}^{+}$) are those with the most favourable energies for the gme cage. In this regard, the tetrahedral $\mathrm{TMA}^{+}$shows a binding energy of $-116 \mathrm{kcal} \mathrm{mol}^{-1}$ which is $20 \mathrm{kcal} \mathrm{mol}^{-1}$ less favourable than that of $\mathrm{HTrMA}^{+}$. Moreover as the number of ethyl groups coordinated to central $\mathrm{N}$ increases, the binding energies become less favourable because the molecules are too big to fit in the gme cage. Figure 2 shows the optimised configuration of each molecule in the gme cage.

Table 2. Binding energies for $\mathrm{HTrMA}^{+}, \mathrm{TMA}^{+}, \mathrm{HEDMA}^{+}, \mathrm{HDEMA}^{+}, \mathrm{DEDMA}^{+}, \mathrm{HTrEA}^{+}$and $\mathrm{TrEMA}^{+}$templates within aluminophosphate gme cage determined by molecular dynamics and energy minimisation calculations.

\begin{tabular}{cc}
\hline SDA & binding energy $\left(\mathbf{k c a l ~ m o l}^{-1}\right)$ \\
\hline $\mathrm{HTrMA}^{+}$ & -136 \\
$\mathrm{TMA}^{+}$ & -116 \\
$\mathrm{HEDMA}^{+}$ & -133 \\
$\mathrm{HDEMA}^{+}$ & -128 \\
$\mathrm{DEDMA}^{+}$ & -74 \\
$\mathrm{HTrEA}^{+}$ & -117 \\
TrEMA $^{+}$ & -63 \\
\hline
\end{tabular}
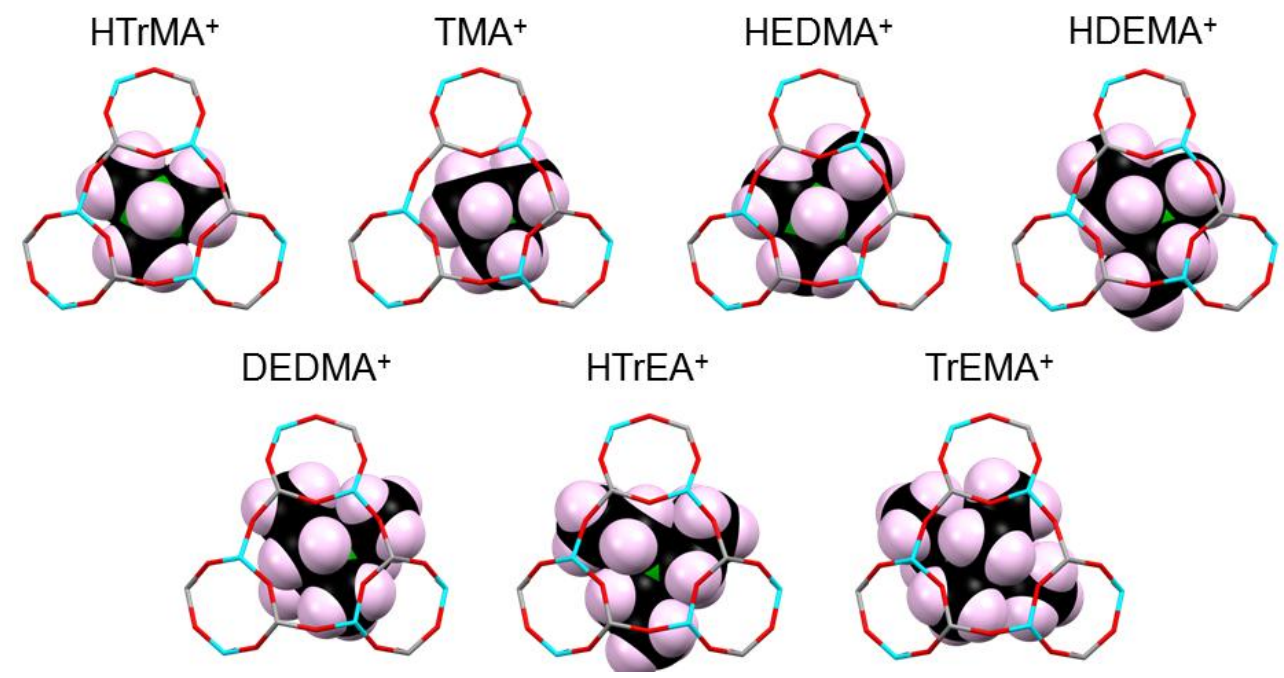

$\operatorname{TrEMA}^{+}$

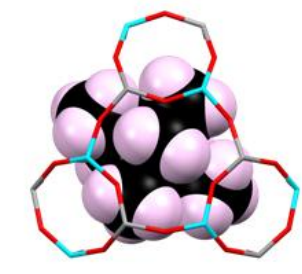

Figure 2. Energy-minimised configurations of quaternary ammonium cations in the gme cage (light blue: $\mathrm{Al}$; grey: $\mathrm{P}$; red: O; black: C; green: $\mathrm{N}$; pink: $\mathrm{H})$. 
On account of its most favourable calculated energy, $\mathrm{HTrMA}^{+}$was chosen as a candidate SDA for the gme cage. Furthermore, in order to investigate possible competition with the formation of other structures containing small cages, $\mathrm{HTrMA}^{+}$and $\operatorname{TrMA}$ were also modelled within gis and sod cages. The binding energies in Table 3 suggest that in both protonated and non-protonated forms, TrMA has a better chance of influencing the formation of gme compared to gis or sod. However, when protonated, TrMA assumed a more tetrahedral conformation which fits into the sod cage better than the non-protonated form. The optimised configurations for each cage are shown in Figure 3.

Table 3. Binding energies for TrMA and $\mathrm{HTrMA}^{+}$within aluminophosphate gme, gis, and sod cages determined by molecular dynamics and energy minimisation calculations.

\begin{tabular}{cccc}
\hline SDA & \multicolumn{3}{c}{ binding energy $\left(\mathrm{kcal} \mathrm{mol}^{-\mathbf{1}}\right)$} \\
& gme & gis & sod \\
\hline TrMA & -17.6 & -9.1 & -15.1 \\
$\mathrm{HTrMA}^{+}$ & -136.2 & -126.3 & -135.0 \\
\hline
\end{tabular}

gme

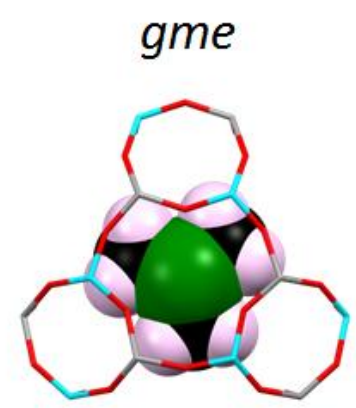

TrMA

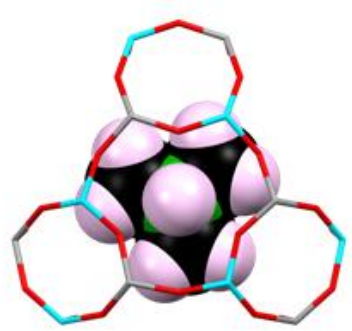

gis
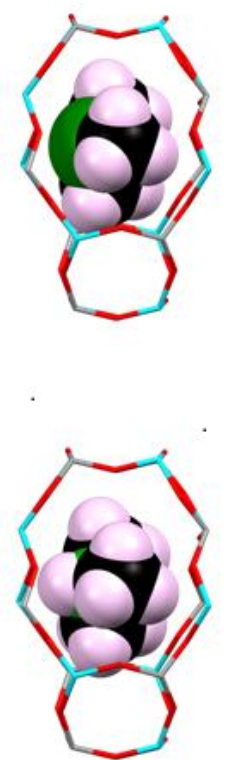

sod
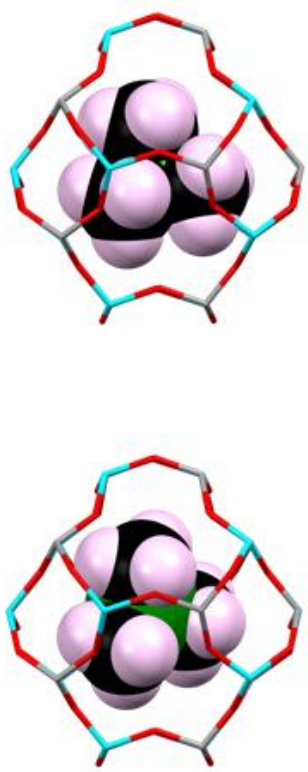

Figure 3. Energy-minimised configurations of TrMA and $\mathrm{HTrMA}^{+}$within aluminophosphate gme, gis and sod cages (light blue: Al; grey: P; red: O; black: C; green: N; pink: $\mathrm{H}$ ). 
The structure-directing effect of adding trimethylamine to a SAPO preparation was investigated. A silicoaluminophosphate gel of composition $\mathrm{Al}(\mathrm{OH})_{3}: 0.8 \mathrm{H}_{3} \mathrm{PO}_{4}: 0.2 \mathrm{SiO}_{2}$ : $0.42 \operatorname{TrMA}: 40 \mathrm{H}_{2} \mathrm{O}$ was heated at $190{ }^{\circ} \mathrm{C}$ for 7 days and gave a mixture of gismondine (SAPO-43 (GIS) and sodalite (SAPO-20 (SOD)) (Figure S1, Supporting Information). No evidence of a SAPO with the GME topology was detected. SOD and GIS frameworks are built only from sod and gis cages, respectively. By contrast, the GME framework contains both gme cages and $12 \mathrm{R}$ channels as regions of low framework density and relatively high energy, requiring stabilisation by SDA incorporation. Therefore, the presence of a second open space in addition to the gme cage (and for which the interaction energy with $\mathrm{HTrMA}^{+}$is less favourable) may result in an increase in the energy of the GME structure in comparison to SOD and GIS structures. The ${ }^{13} \mathrm{C}$ MAS NMR spectrum of the mixture shows (Figure 4) a dominant signal at $47 \mathrm{ppm}$ characteristic of trimethylammonium, $\left(\mathrm{CH}_{3}\right)_{3} \mathrm{NH}^{+}$, ${ }^{45}$ with signals at 37 and $39 \mathrm{ppm}$ belonging to dimethylamine, $\left(\mathrm{CH}_{3}\right)_{2} \mathrm{NH}$, and protonated dimethylamine, $\left(\mathrm{CH}_{3}\right)_{2} \mathrm{NH}_{2}{ }^{+46} \mathrm{~A}$ minor resonance at $58 \mathrm{ppm}$ is assigned to tetramethylammonium, $\left(\mathrm{CH}_{3}\right)_{4} \mathrm{~N}^{+} .{ }^{47}$ The formation of dimethylamine and tetramethylammonium via transmethylation might be associated with the synthetic conditions (high temperature and pressure) and/or to the catalytic activity of the crystallised SAPOs (SOD and GIS). ${ }^{15} \mathrm{~N}$ MAS NMR was performed to investigate the protonation state of the $\mathrm{N}$ atom of trimethylamine within the as-prepared material. Potentially, five different signals belonging to trimethylamine, protonated trimethylamine, dimethylamine, protonated dimethylamine and tetramethylammonium may be present in the spectrum. However, the spectrum in Figure 4 shows only two resonances: the most intense at $-348 \mathrm{ppm}$ was assigned to protonated trimethylamine, $\left(\mathrm{CH}_{3}\right)_{3} \mathrm{NH}^{+}$, while that at $-356 \mathrm{ppm}$ was assigned to protonated dimethylamine, $\left(\mathrm{CH}_{3}\right)_{2} \mathrm{NH}_{2}{ }^{+}$. The attribution of the two signals is based on the computational and experimental data reported by Castro et al. for diDABCO-C4 within AlPO STA-2. ${ }^{48}$ 
Their results suggest the following chemical shifts: $-332 \mathrm{ppm}$ for $\mathrm{NR}_{4}{ }^{+},-350 \mathrm{ppm}$ for $\mathrm{NR}_{3} \mathrm{H}^{+}$ and -375 ppm for $\mathrm{NR}_{3}$, in line with other studies. ${ }^{49}$
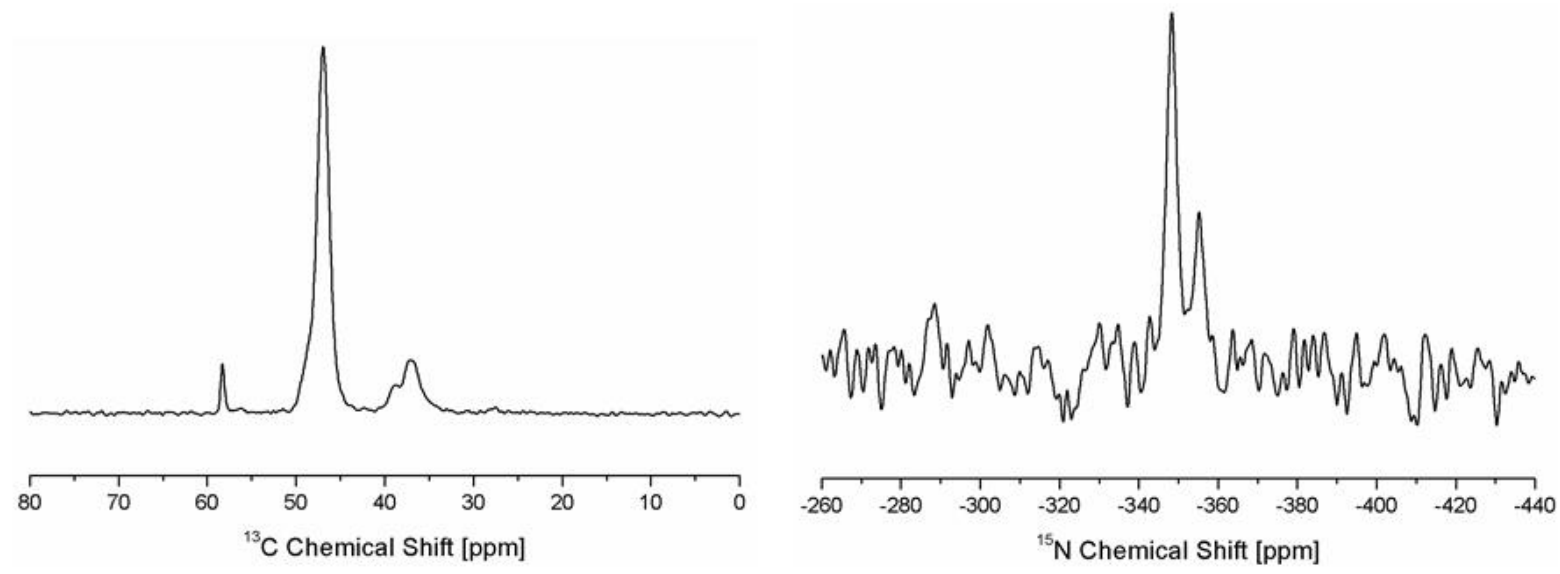

Figure 4. (Left) ${ }^{13} \mathrm{C}$ and (right) ${ }^{15} \mathrm{~N}$ MAS NMR spectra for the SAPO prepared using TrMA as SDA.

\subsection{Co-templating SAPO-56 (AFX)}

The combination of trimethylamine and diDABCO-C4 SDAs was used to target the AFX structure, which contained gme and aft cages: aft cages in the aluminosilicate SSZ-16 are known to be templated by diDABCO-C4. ${ }^{50}$ The combination was found to be successful for the preparation of SAPO-56 using gels with $\mathrm{Si} / \mathrm{Al}>0.2$ : for $\mathrm{Si} / \mathrm{Al}<0.2$ impurities of AlPO-5 and an unidentified aluminophosphate phase (composition by SEM/EDX) were present (Figure S3). The requirement for overall charge balance between the framework and OSDAs may help explain the need for an elevated Si concentration. At $\mathrm{pH} 7$ (pH of the starting gel) trimethylamine is likely to be present in its protonated form, trimethylammonium, while diDABCO-C4 is in its dicationic form. ${ }^{48}$ Considering $\mathrm{P}^{5+}$ substitution by $\mathrm{Si}^{4+}$ as the mechanism for the incorporation of silicon atoms within the framework, a Si/Al ratio of 0.2 is insufficient to balance the six positive charges of OSDAs per unit cell (considering one 
TrMA and one diDABCO-C4 for each of the two gme and two aft cages). An idealised unit cell composition for SAPO-56 would then be $\left[\mathrm{diDABCO}-\mathrm{C}^{2+}\right]_{2}\left[\mathrm{HTrMA}^{+}\right]_{2} \mathrm{Al}_{24} \mathrm{P}_{18} \mathrm{Si}_{6} \mathrm{O}_{96}$.

To understand the involvement of TrMA during the synthesis of SAPO-56, its concentration was varied within the starting gels while ensuring a starting $\mathrm{pH}$ of 7 by adding different amounts of TBAOH. Pure SAPO-56 was only obtained at a TrMA/Al ratio of ca. 0.2 and not in its absence (Figure S4). These results prove the crucial structure-directing role of TrMA in the formation of SAPO-56 under these conditions and show that careful adjustment of the amount of TrMA added to the gel is required to prevent the co-crystallisation of additional phases.

TBAOH was chosen as a $\mathrm{pH}$ modifying co-base because its shape and dimensions do not favour its action as an SDA (although AlPO-5 and MeAPO-5 (AFI), ${ }^{51}$ MeAPO-11 (AEL), MeAPO-41 (AFO) and MeAPO-42 (LTA) have been reported to form in its presence). ${ }^{52} \mathrm{We}$ found tetrapropylammonium hydroxide (TPAOH) had the same effect, but if tetrapentylammonium hydroxide (TPeAOH) was used, AlPO-5 co-crystallised (Figure S5) possibly due to the templating action of its decomposition fragments.

As reported previously, ${ }^{48}$ diDABCO-C3 and diDABCO-C5 show non-bonding energies of interaction within AIPO AFX comparable to that of diDABCO-C4. Both diquaternary molecules were tested together with trimethylamine for the synthesis of SAPO-56. SAPO-17 (ERI) and SAPO-34 (CHA) resulted with diDABCO-C3 while SAPO-56 (AFX) crystallised together with an unidentified aluminophosphate phase in the presence of diDABCO-C5 (Figure S6). The formation of SAPO-17 can be associated with the length of the carbon chain: the aft cage contains an additional set of four-rings with respect to the eri cage (it is ca. $3 \AA$ longer). Further optimisation of the Si content of the gel containing diDABCO-C5 enabled pure SAPO-56 to be obtained ( $\mathrm{Si} / \mathrm{Al}=0.29$, Figure $\mathrm{S7}$ ). Elemental analyses suggest 
that TrMA and diDABCO-C4 or diDABCO-C5 were both incorporated intact within SAPO56 (AFX) which contains 2 gme and 2 aft cages per unit cell. The crystal morphologies of SAPO-56 synthesised with diDABCO-C4 and diDABCO-C5 are reported in Figure S8. In both samples the crystals have an uneven hexagonal morphology with an average side of length $40 \mu \mathrm{m}$. The calculated chemical compositions are reported in Table 4. Silica species within the pores or on the surface of the crystals may affect the measured $\mathrm{Si}$ atomic $\%$.

Table 4. Approximate unit cell composition of SAPO AFX samples based on EDX, CHN and TGA analysis.

\begin{tabular}{cccc}
\hline SDA & $\begin{array}{c}\mathrm{C} / \mathrm{N}^{\mathrm{a}} \\
(\text { calc })\end{array}$ & $\begin{array}{c}\mathrm{C} / \mathrm{N} \\
(\exp )\end{array}$ & $\begin{array}{c}\text { unit cell composition } \\
\text { (by EDX, TGA) }\end{array}$ \\
\hline diDABCO-C4 & 3.26 & 3.23 & {$[\text { diDABCO-C4 }]_{1.9}[\operatorname{TrMA}]_{1.9} \mathrm{Al}_{24} \mathrm{P}_{17.2} \mathrm{Si}_{6.8} \mathrm{O}_{96} 4 \mathrm{H}_{2} \mathrm{O}$} \\
diDABCO-C5 & 3.43 & 3.40 & {$[\text { diDABCO-C5 }]_{1.5}\left[\operatorname{TrMA}_{1.5} \mathrm{Al}_{24} \mathrm{P}_{15.6} \mathrm{Si}_{8.4} \mathrm{O}_{96}{ }_{2} \mathrm{H}_{2} \mathrm{O}\right.$} \\
\hline
\end{tabular}

${ }^{\text {a }}$ The $\mathrm{C} / \mathrm{N}$ composition was calculated assuming a $1: 1$ ratio of TrMA and diDABCO templates.

The SAPO-56 samples were calcined at $600{ }^{\circ} \mathrm{C}$ in a dry oxygen flow in order to remove the organic SDAs, without significant decrease in the measured crystallinity (Figure S9). The porosity of the calcined solids was established by the measurement of adsorption isotherms for $\mathrm{N}_{2}$ at $-196.15{ }^{\circ} \mathrm{C}$ (Figure $\left.\mathrm{S} 10\right) . \mathrm{N}_{2}$ uptakes at $\mathrm{p} / \mathrm{p}_{0}=0.2$ indicated pore volumes of 0.17 $\mathrm{cm}^{3} \mathrm{~g}^{-1}$, comparable to those reported in the literature. ${ }^{53}$

Solid-state MAS NMR spectra were recorded on dehydrated as-synthesised and calcined samples. The ${ }^{13} \mathrm{C}$ MAS NMR spectra (Figure 5) show that in both cases the diDABCO template and the TrMA are incorporated intact within the SAPO-56. The ${ }^{27}$ Al MAS NMR spectra of as-prepared samples (Figure S11) show two peaks, a major one at 38.7 to $37.6 \mathrm{ppm}$ and a minor one at 8.2 to $7.4 \mathrm{ppm}$, assigned to tetrahedral and five-fold coordinated $\mathrm{Al}$ atoms, respectively. Due to the absence of water in the dehydrated samples, the additional coordination is likely to be from charge-balancing hydroxyl groups. This is supported by the 
disappearance of the corresponding resonance after calcination. The ${ }^{31} \mathrm{P}$ MAS NMR spectra (Figure S11) of as-prepared samples show a resonance at $-28.3 \mathrm{ppm}$ typical of tetrahedral $\mathrm{P}(\mathrm{OAl})_{4}$. A weak shoulder at about $-22.6 \mathrm{ppm}$ is present in both spectra. This resonance has been observed previously in SAPO-56 and assigned to local geometry changes due to the silicon substitution, hydroxyl groups attached to neighbouring $\mathrm{Al}$ or minor amorphous components. ${ }^{35}$ Template removal results in a small upfield shift. ${ }^{29} \mathrm{Si}$ MAS NMR spectra of as-prepared samples (Figure S11) have a single sharp peak at about -90.5 ppm, corresponding to $\mathrm{Si}(\mathrm{OAl})_{4}$, which indicates that the $\mathrm{Si}$ mainly substitutes for $\mathrm{P}$ in the lattice. The signals in the ${ }^{29} \mathrm{Si}$ spectra of the calcined materials are slightly broadened, suggesting some loss of short range order.
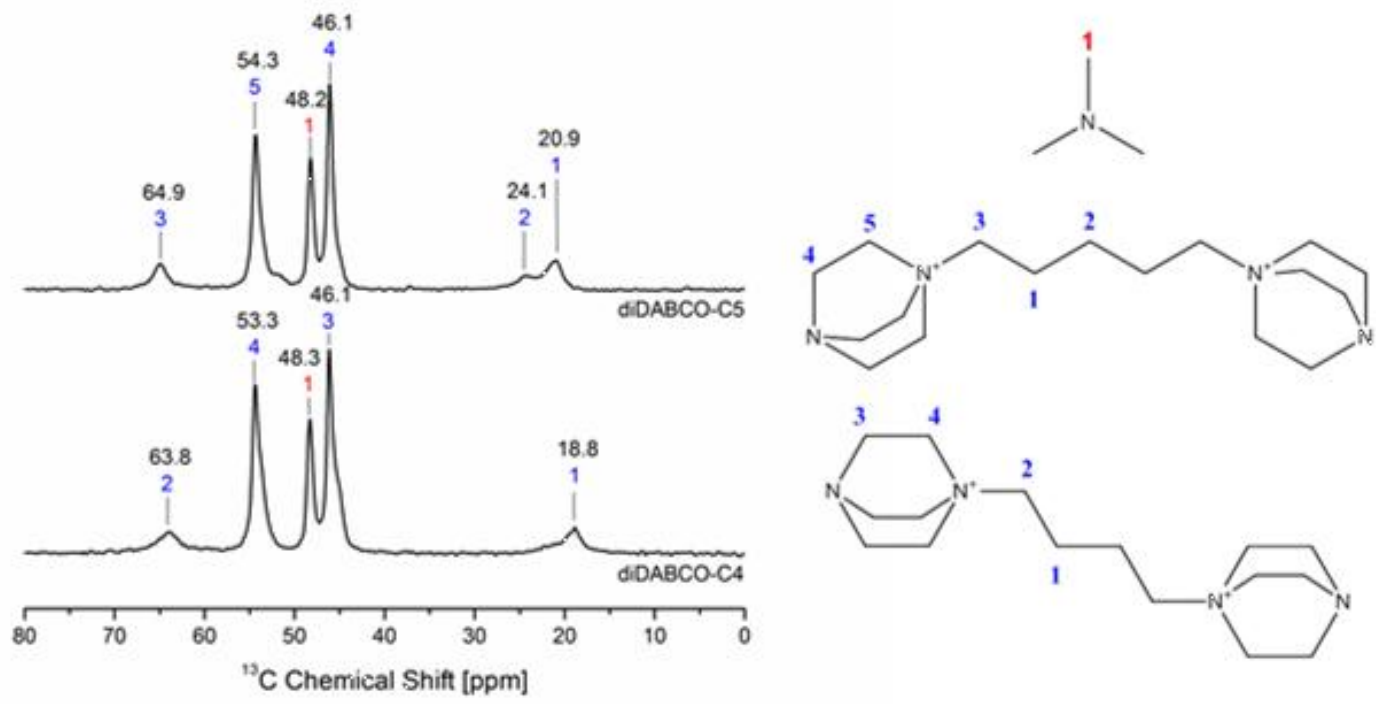

Figure 5. ${ }^{13} \mathrm{C}$ solid-state MAS NMR spectra for dehydrated as-prepared SAPO-56 samples synthesised using trimethylamine and either diDABCO-C4 or diDABCO-C5 as SDAs.

SAPO-56 containing TrMA and diDABCO-C4 in their energy-minimised positions within the two gme and two aft cages was used as a starting model for the Rietveld refinement against XRD data. The sample was fully dehydrated before data was collected. The 
refinement with geometric restraints imposed on the bond distances of the atoms in the framework, proceeded smoothly and converged with $R_{F}{ }^{2}=0.122$ and $R_{w p}=0.058\left(\mathrm{R}_{\mathrm{p}}=\right.$ 0.043). Towards the end of the refinement, the O-O bond restraints were fully removed. The positions of both templates were kept constant and only their occupancy was allowed to refine. The final occupancies suggest 1.9 TrMA and 1.95 diDABCO-C4 per unit cell. This result is in agreement with the estimated chemical composition. The framework structure showing the location of the two SDAs within the respective cages (disordered over symmetry related, partially occupied sites) is given in Figure 6.

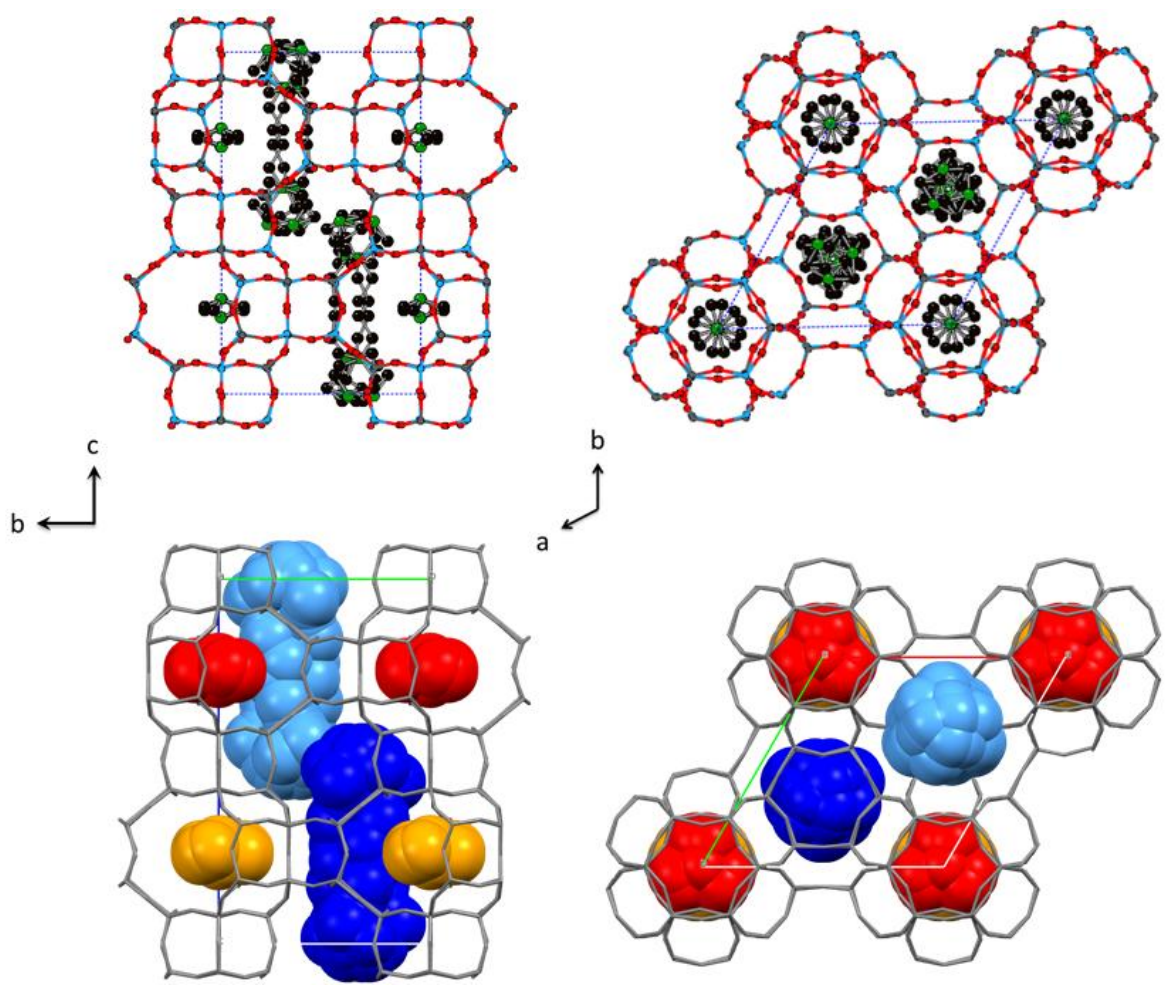

Figure 6. Structure of as-prepared SAPO-56, viewed down $a$ - and $c$-axes, with ball-and-stick (top) and space filling (bottom) representations of trimethylamine and diDABCO-C4 in the gme and aft cages (light blue: $\mathrm{Al}$; grey: $\mathrm{P}$; red: $\mathrm{O}$; black: $\mathrm{C}$; green: $\mathrm{N}$; pink). In the ball-and-stick representations the $\mathrm{H}$ atoms are omitted for clarity. 
The structure of calcined and dehydrated SAPO-56 was refined using XRD data from the material synthesised using TrMA and diDABCO-C4 $\left({ }^{27} \mathrm{Al}\right.$ and ${ }^{31} \mathrm{P}$ MAS NMR indicate the framework cations are fully tetrahedrally-coordinated, following loss of hydroxyl groups attached to Al). Details are given in Table 5 and Rietveld plots in Figure 7. The unit cell of as-prepared SAPO-56 changes from $a=b=13.61328(11) \AA, c=20.2490(4) \AA$ to $a=b=$ 13.75940(31) $\AA, c=19.7610(10) \AA$ upon loss of the OSDAs (diDABCO-C4 and TrMA) and hydroxyl groups. The final atomic coordinates and thermal parameters for as-prepared and calcined SAPO-56 are listed in Tables S1 and S3. Their selected interatomic lengths and angles are summarised in Tables S2 and S4. 
Table 5. Crystallographic data for as-prepared and calcined dehydrated SAPO-56 synthesised using trimethylamine and diDABCO-C4 as SDAs.

\begin{tabular}{|c|c|c|}
\hline & $\begin{array}{l}\text { SAPO-56 (diDABCO-C4) } \\
\text { as-prepared, dehydrated }\end{array}$ & $\begin{array}{l}\text { SAPO-56 (diDABCO-C4) } \\
\text { calcined, dehydrated }\end{array}$ \\
\hline Chemical composition & $\begin{array}{l}\text { [diDABCO-C4 }]_{1.9}[\mathrm{TrMA}]_{1.9} \\
\mathrm{Al}_{24} \mathrm{P}_{17.2} \mathrm{Si}_{6.89} \mathrm{O}_{96}\end{array}$ & $\mathrm{Al}_{24} \mathrm{P}_{17.2} \mathrm{Si}_{6.8} \mathrm{O}_{96}$ \\
\hline \multicolumn{3}{|l|}{ Data collection } \\
\hline Wavelength / § & 1.54056 & 1.54056 \\
\hline Diffractometer geometry & Debye-Scherrer & Debye-Scherrer \\
\hline Sample & Spinning $0.7 \mathrm{~mm}$ capillary & Spinning $1.0 \mathrm{~mm}$ capillary \\
\hline Scanned region $/ 2 \theta^{\circ}$ & $3.0-80.0$ & $3.0-80.0$ \\
\hline Step size $/ 2 \theta^{\circ}$ & 0.01 & 0.01 \\
\hline \multicolumn{3}{|l|}{ Unit cell } \\
\hline Chemical formula & $\begin{array}{l}{\left[\mathrm{N}_{0.95} \mathrm{C}_{2.9} \mathrm{H}_{8.7}\right]_{2}\left[\mathrm{~N}_{3.9} \mathrm{C}_{15.5} \mathrm{H}_{31}\right]_{2}} \\
\mathrm{Al}_{24} \mathrm{Si}_{6} \mathrm{P}_{18} \mathrm{O}_{96}\end{array}$ & $\mathrm{Al}_{24} \mathrm{Si}_{6} \mathrm{P}_{18} \mathrm{O}_{96}$ \\
\hline Crystal system & trigonal & trigonal \\
\hline Space group & $P-31 c$ & $P-31 c$ \\
\hline$a / \AA$ & $13.61328(11)$ & $13.75940(31)$ \\
\hline$b / \AA$ & $13.61328(11)$ & $13.75940(31)$ \\
\hline$c / \AA$ & $20.2490(4)$ & $19.7610(10)$ \\
\hline Volume / $\AA^{3}$ & $3249.82(13)$ & $3239.95(17)$ \\
\hline \multicolumn{3}{|l|}{ FWHM $^{\mathrm{a}}$} \\
\hline$(004) / \circ$ & 0.255 & 0.233 \\
\hline$(212) / \circ$ & 0.218 & / \\
\hline$(101) / \circ$ & / & 0.241 \\
\hline Background & Graphically 32 terms & Chebyschev 32 terms \\
\hline$R_{\mathrm{wp}}$ & 0.058 & 0.060 \\
\hline$R_{\mathrm{p}}$ & 0.043 & 0.047 \\
\hline$R_{\mathrm{F}}^{2}$ & 0.122 & 0.156 \\
\hline$X^{2}$ & 1.85 & 2.41 \\
\hline
\end{tabular}

${ }^{a}$ The (004) reflection (or more specifically the (001) family) is not affected by possible stacking faults while the (212) and (101) reflections correspond to the major peaks of as-prepared and calcined SAPO-56. 

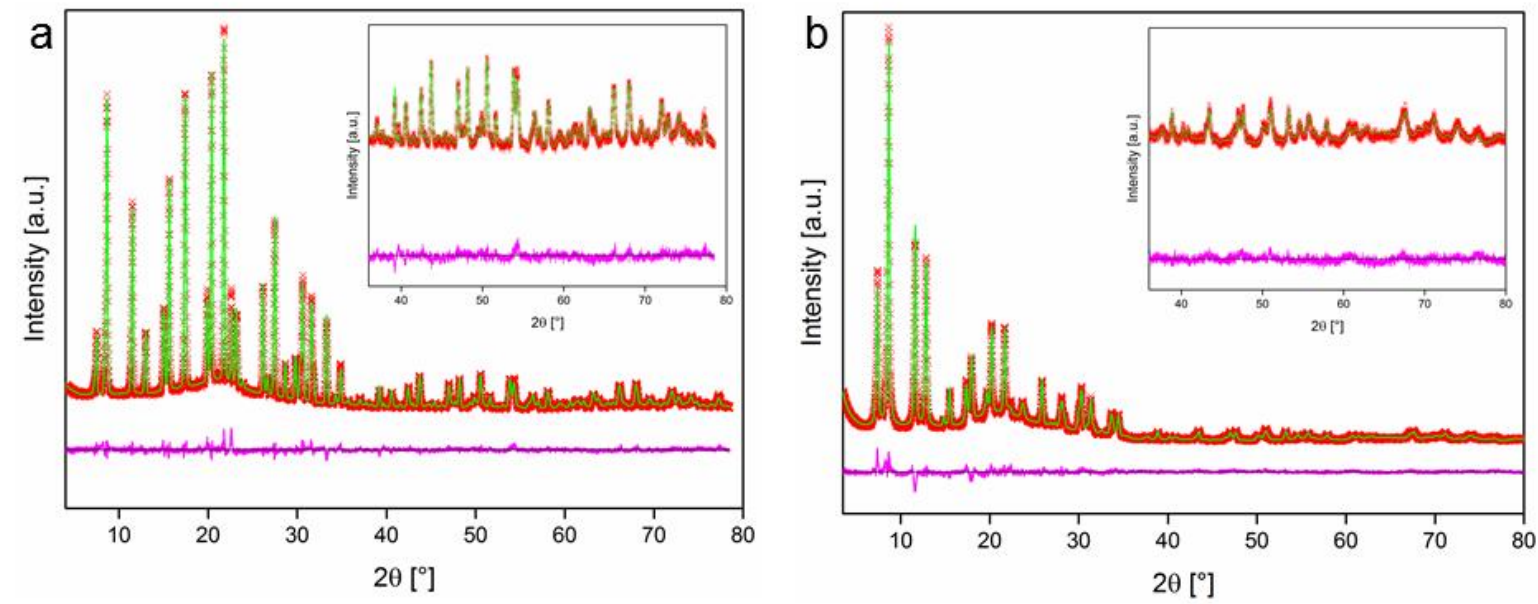

Figure 7. Rietveld plots for (a) as-prepared and (b) calcined, dehydrated SAPO-56 synthesised using trimethylamine and diDABCO-C4 as SDAs (observed data (red crosses), calculated fit (green line), and difference plot (purple line)).

Very recent work by Liu et al. ${ }^{37}$ reports the synthesis of SAPO-56 during the aminothermal synthesis in a mixture of TrMA and TrEA, added in an exploratory way. Both organic molecules were found to be included in the product, and their modelling (like ours) suggested that trimethylamine is located preferentially within the gme cages.

\subsection{Co-templating SAPO (SFW) (STA-18)}

As mentioned above, the SFW framework was synthesised as an aluminosilicate (SSZ-52) using a polycyclic quaternary ammonium cation (N,N-diethyl-5,8-dimethyl-2-azonium bicyclo[3.2.2]nonane) as a structure-directing agent. ${ }^{38}$ HRTEM and XRD simulations show $5-10 \%$ stacking faults within the structure. The template is too small to fill the large $s f w$ cage. Molecular modelling and Rietveld refinement indicate two quaternary ammonium cations per $s f w$ cage while a single molecule or a cluster of three alkylammonium cations 
might template a cha or a longer cavity, respectively, with consequent formation of stacking faults. More recently, ${ }^{54}$ alternative SDAs have been found for this zeolite using the computerassisted method of Deem ${ }^{24}$ using larger molecules (not including the diDABCO cations of this work) that singly better fill the cavity, although the reported PXRD patterns indicate considerable peak broadening remains.

Following the positive results obtained with SAPO-56, the double-template approach has been used to prepare the SAPO version of SFW. In order to find a suitable SDA for the $s f w$ cage ( $c a .5 \AA$ longer than an aft cage), the binding energies of diDABCO cations with different carbon chain lengths have been determined by molecular mechanics calculations. The torsion energy was also calculated, giving information about the ease of fit of the organic molecules within the structure. The diDABCO SDAs were also modeled within the aft cage of the AFX framework, so that the predicted selectivity of synthesis of the longer $s f w$ cages could be examined (Table 6).

Table 6. Binding and torsion energies for $\operatorname{diDABCO}$ templates within the larger aluminophosphate cages of SFW and AFX frameworks, as determined by molecular dynamics and energy minimisation calculations.

\begin{tabular}{|c|c|c|c|c|}
\hline \multirow[t]{2}{*}{ SDA } & \multicolumn{2}{|c|}{ binding energy $\left(\mathrm{kcal} \mathrm{mol}^{-1}\right)$} & \multicolumn{2}{|c|}{ torsion energy $\left(\mathrm{kcal} \mathrm{mol}^{-1}\right)$} \\
\hline & SFW & AFX & SFW & AFX \\
\hline diDABCO-C3 & -120 & -204 & 0.1 & 0.1 \\
\hline diDABCO-C4 & -135 & -189 & 0.0 & 0.2 \\
\hline diDABCO-C5 & -140 & -170 & 0.0 & 0.1 \\
\hline diDABCO-C6 & -155 & -138 & 0.1 & 4.3 \\
\hline diDABCO-C7 & -134 & - & 0.2 & - \\
\hline diDABCO-C8 & -139 & - & 1.9 & - \\
\hline
\end{tabular}

DiDABCO-C6 gives a binding energy of $-155 \mathrm{kcal} \mathrm{mol}^{-1}$ within the $s f w$ cage, which is more favourable than the $-138 \mathrm{kcal} \mathrm{mol}^{-1}$ calculated within the aft cage where this diquaternary 
dication is slightly too large. Furthermore the torsion energy of $4.3 \mathrm{kcal} \mathrm{mol}^{-1}$ suggests that diDABCO-C6 needs to twist significantly to fit into the aft cage. Although diDABCO-C5 shows a favourable binding energy for the $s f w$ cage $\left(-140 \mathrm{kcal} \mathrm{mol}^{-1}\right)$, the $-170 \mathrm{kcal} \mathrm{mol}^{-1}$ shown for the aft cage makes it less attractive as a possible candidate SDA for the synthesis of SAPO SFW. Figure 8 shows the minimised configurations of the DABCO-based SDAs within aluminophosphate aft and $s f w$ cages of the AFX and SFW frameworks.
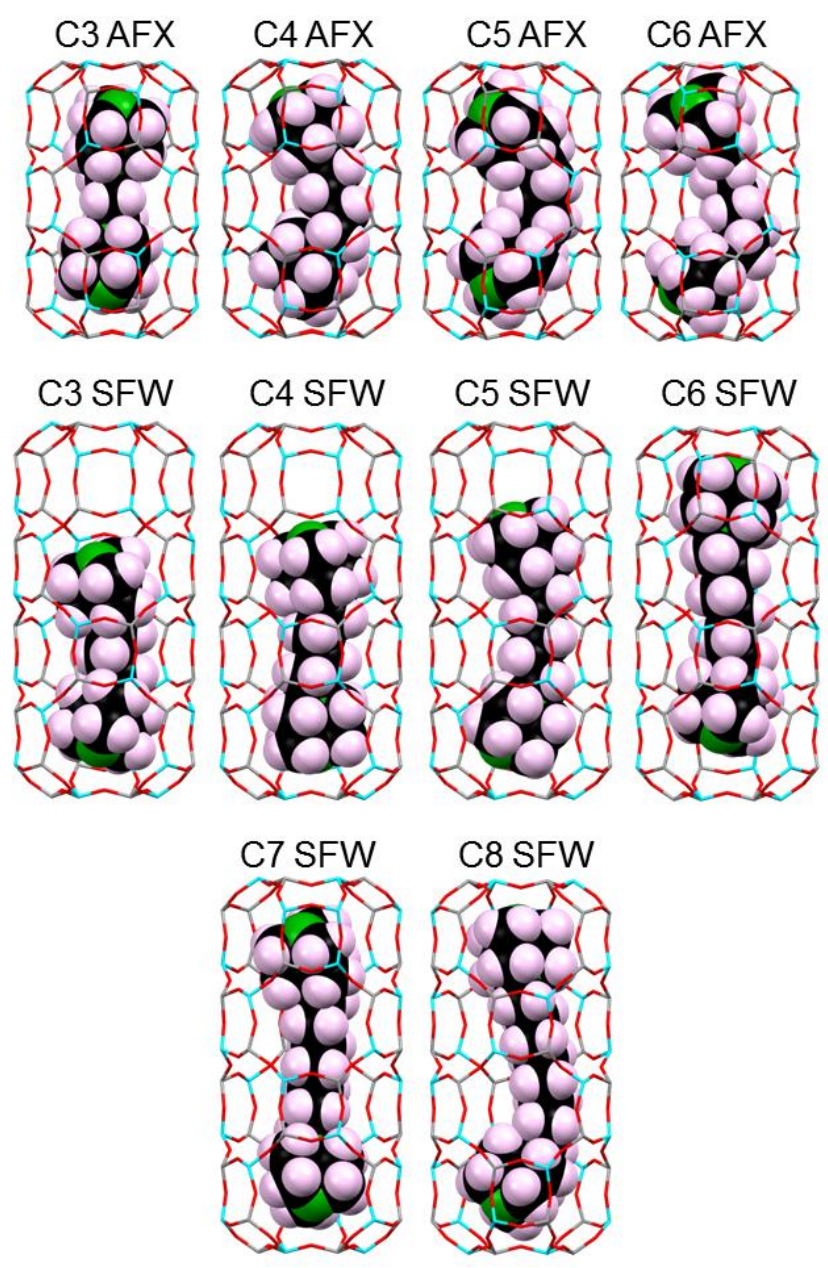

Figure 8. Energy-minimised configurations of diDABCO-based SDAs with different polymethylene chain length in aluminophosphate cages in the AFX and SFW frameworks (light blue: Al; grey: P; red: O; black: C; green: N; pink: H). 
Attempts to prepare SAPO (SFW) were performed using diDABCO-C6 and TrMA as SDAs, $\mathrm{TBAOH}$ as co-base and by varying the $\mathrm{Si} / \mathrm{Al}$ ratio of the starting gel. Comparison between the PXRD patterns and the simulated pattern of ideal, fault-free SSZ-52 shows that pure SAPO (SFW) (denoted STA-18) was obtained with a Si/Al ratio of 0.3 (Figure S12). When the $\mathrm{Si} / \mathrm{Al}$ ratio was reduced, additional unknown phases co-crystallised together with STA18. The success of this synthesis underlines the potential of our method of design and synthesis of target structures using two different SDAs. Furthermore, the absence of broad peaks in the PXRD diffractogram suggests that the SAPO (SFW) obtained is free of stacking faults.

As in the synthesis of SAPO-56, the role played by trimethylamine during the synthesis of SAPO STA-18 was investigated by changing its concentration within the gel, again adjusting the $\mathrm{pH}$ with TBAOH (Figure S13). Pure SAPO STA-18 is formed only at TrMA/Al of ca. 0.13, and without TrMA no STA-18 is formed. ${ }^{13} \mathrm{C}$ MAS NMR (Figure 9) indicates TBAOH is not incorporated within the SAPO (SFW). Replacement of TBAOH with TPAOH or TPeAOH resulted in the formation of SAPO-5 as an impurity phase (Figure S14).

The molecular mechanics calculations showed that diDABCO-C7 and diDABCO-C8 have a reasonable fit within the $s f w$ cage, although their binding energies are $c a \cdot 15-20 \mathrm{kcal} \mathrm{mol}^{-1}$ higher than that of diDABCO-C6 (diDABCO-C8 also shows a higher torsion energy, of 1.9 $\mathrm{kcal} \mathrm{mol}^{-1}$ ). These diquaternary dications were therefore used, together with TrMA, in the attempt to prepare SAPO (SFW). Pure SFW crystallises with both diDABCO-C7 and diDABCO-C8 (Figure S15). Moreover the diffraction patterns suggest that in these cases the SFW structures obtained are also fault-free.

The template content determined by CHN and TGA shows that in all three SAPO STA-18 samples the 6 gme and 3 sfw cages of SFW unit cell are almost fully occupied by 
trimethylamine and diDABCO-C $(6,7,8)$, respectively. The overall chemical composition determined for the three as-prepared materials is reported in Table 7. As is the case for SAPO-56, silicon species on the surface of the crystals may result in over-estimation of the atomic \% of Si when measured by EDX.

Table 7. Approximate unit cell composition of SAPO STA-18 samples based on EDX, CHN and TGA analysis.

\begin{tabular}{cllc}
\hline SDA & $\begin{array}{l}\mathrm{C} / \mathrm{N}^{\mathrm{a}} \\
(\mathrm{calc})\end{array}$ & $\begin{array}{l}\mathrm{C} / \mathrm{N} \\
(\mathrm{exp})\end{array}$ & $\begin{array}{c}\text { unit cell composition } \\
\text { (by EDX, TGA) }\end{array}$ \\
\hline diDABCO-C6 & 3.43 & 3.40 & {$[\text { diDABCO-C6 }]_{2.8}[\mathrm{TrMA}]_{5.7} \mathrm{Al}_{54} \mathrm{P}_{35.9} \mathrm{Si}_{18.1} \mathrm{O}_{216} 18 \mathrm{H}_{2} \mathrm{O}$} \\
diDABCO-C7 & 3.57 & 3.54 & {$[\text { diDABCO-C7 }]_{2.9}[\mathrm{TrMA}]_{5.8} \mathrm{Al}_{54} \mathrm{P}_{36.6} \mathrm{Si}_{17.4} \mathrm{O}_{216} 13 \mathrm{H}_{2} \mathrm{O}$} \\
diDABCO-C8 & 3.72 & 3.68 & {$[\text { diDABCO-C }]_{2.8}[\mathrm{TrMA}]_{5.6} \mathrm{Al}_{54} \mathrm{P}_{24.7} \mathrm{Si}_{29.3} \mathrm{O}_{216} 13 \mathrm{H}_{2} \mathrm{O}$} \\
\hline
\end{tabular}

${ }^{\mathrm{a}}$ The $\mathrm{C} / \mathrm{N}$ composition was calculated assuming $2: 1$ ratio of TrMA and diDABCO templates.

The hexagonal prismatic morphology of SAPO STA-18 synthesised with trimethylamine and the three diDABCO SDAs is shown in Figure S16. For SAPO STA-18 obtained using diDABCO-C8, some amorphous material is present even after sonication, as shown by the higher background in the PXRD pattern. We attribute this to the imperfect fit of diDABCOC8 within the sfw cage.

The crystallinity of the samples was not strongly affected by the template removal at $600{ }^{\circ} \mathrm{C}$ in a dry oxygen flow (Figure S17). Nitrogen adsorption on the three calcined samples of SAPO STA-18 gave uptakes at $\mathrm{p} / \mathrm{p}_{0}=0.2$ corresponding to pore volumes of $0.17,0.17$ and $0.10 \mathrm{~cm}^{3} \mathrm{~g}^{-1}$, respectively (Figure $\mathrm{S} 18$ ). The lower value for diDABCO-C8 is attributed to the presence of amorphous material.

Solid-state MAS NMR spectra were recorded on dehydrated as-synthesised and calcined samples. The resonances present in the ${ }^{13}$ C MAS NMR spectra (Figure 9) are consistent with the incorporation of both TrMA and the diDABCO template within cages in the SFW 
structure. The ${ }^{27} \mathrm{Al},{ }^{31} \mathrm{P}$ and ${ }^{29} \mathrm{Si}$ MAS NMR spectra show similar features to those seen for SAPO-56 described previously. Details are given in the caption for Figure S19.
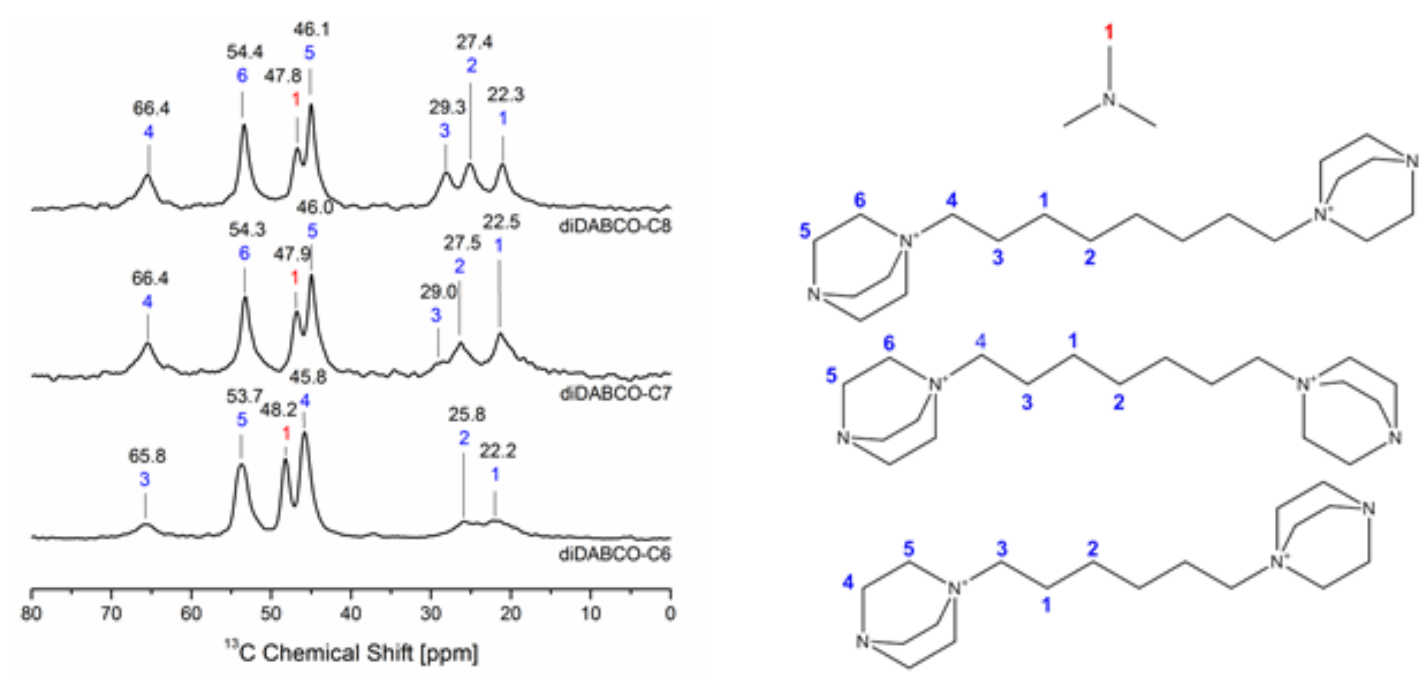

Figure 9. ${ }^{13} \mathrm{C}$ solid-state MAS NMR spectra for dehydrated as-prepared SAPO STA-18 samples synthesised using trimethylamine and diDABCO-C6 (bottom), diDABCO-C7 (middle) or diDABCOC8 (top), with suggested peak assignments.

The expected positions of TrMA and diDABCO-C6 within the six gme and three sfw cages per SFW unit cell, respectively, have been predicted by molecular modelling (Figure 10). The resultant structural model was used for the Rietveld refinement of the structure of dehydrated as-prepared SAPO (SFW) (Figure 11a and Table 8). The refined occupancies of the two SDAs suggest 5.4 TrMA and 2.9 diDABCO-C6 per unit cell, in close agreement with those estimated from chemical composition. 


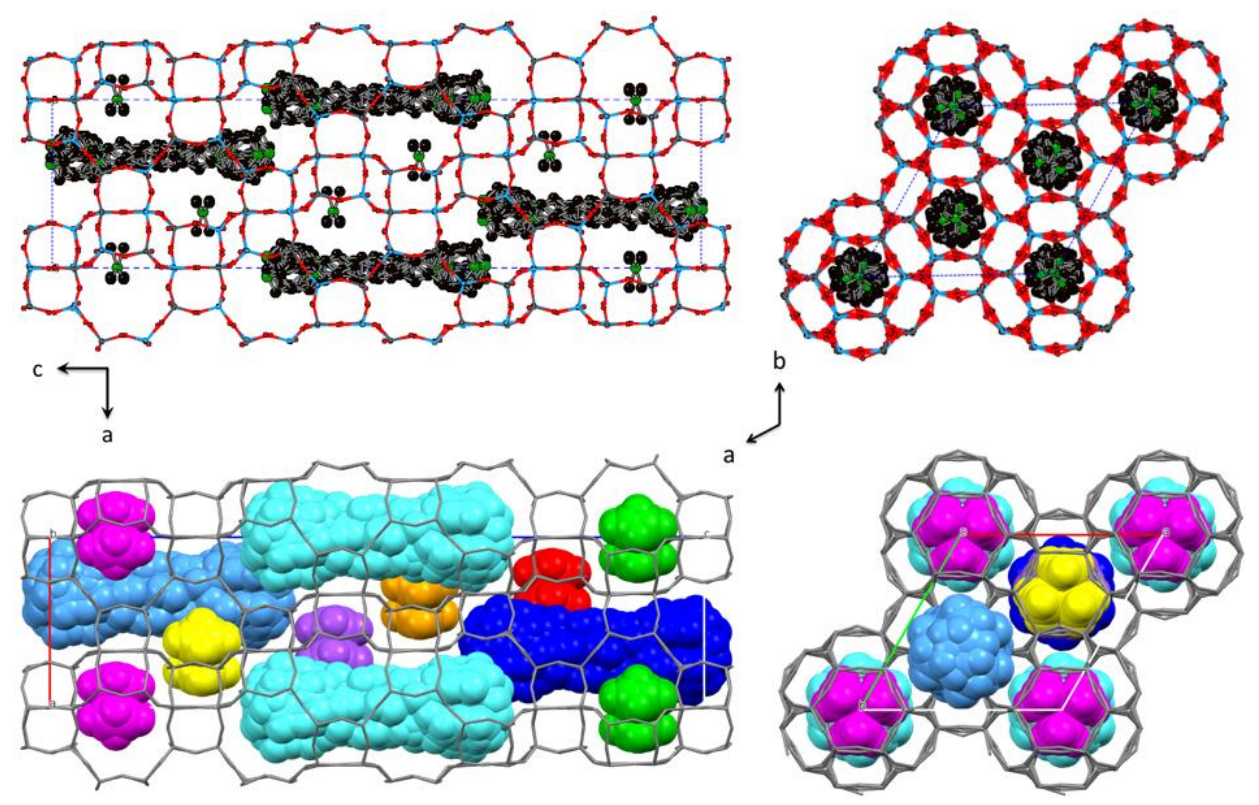

Figure 10. Structure of as-prepared SAPO STA-18, with ball-and-stick (top) and space-filling (bottom) representations of trimethylamine and diDABCO-C6 in the gme and sfw cages (light blue: $\mathrm{Al}$; grey: $\mathrm{P}$; red: $\mathrm{O}$; black: $\mathrm{C}$; green: $\mathrm{N}$ ). In the ball-and-stick representation the $\mathrm{H}$ atoms are omitted for clarity.

Furthermore the X-ray powder diffraction data measured for calcined and dehydrated SAPO (SFW) for all three materials obtained with diDABCO-C6, -C7 and -C8 were used to confirm the framework structure and to refine the tetrahedral framework positions. A good fit to the data was obtained for all three samples. Similarly to the change observed upon calcination of SAPO-56, the unit cell of as-prepared SAPO STA-18 changed from $a=b=13.64075(31) \AA$, $c=45.4999(13) \AA$ to $a=b=13.79540(18) \AA, c=44.6461(15) \AA$ upon loss of the OSDAs (diDABCO-C6 and TrMA) and charge-balancing hydroxyl groups. The crystallographic data and refinement plots for as-prepared and calcined SAPO STA-18 prepared with TrMA and diDABCO-C6 are given in Table 8 and Figure 11, respectively. Those for the calcined SAPO STA-18 samples prepared with TrMA and diDABCO-C7 or C8 are reported in Table S5 and Figure S20. The final atomic coordinates and thermal parameters for as-prepared and 
calcined SAPO STA-18 are listed in Tables S6, S8, S10 and S12. Selected interatomic lengths and angles are summarised in Tables S7, S9, S11 and S13.

Table 8. Crystallographic data for as-prepared and calcined dehydrated SAPO STA-18 synthesised using trimethylamine and diDABCO-C6 as SDAs.

\begin{tabular}{|c|c|c|}
\hline & $\begin{array}{l}\text { SAPO STA-18 (diDABCO-C6) } \\
\text { as-prepared, dehydrated }\end{array}$ & $\begin{array}{l}\text { SAPO STA-18 (diDABCO-C6) } \\
\text { calcined, dehydrated }\end{array}$ \\
\hline Chemical composition & $\begin{array}{l}{[\text { diDABCO-C6 }]_{2.8}[\mathrm{TrMA}]_{5.7}} \\
\mathrm{Al}_{54} \mathrm{P}_{35.9} \mathrm{Si}_{18.1} \mathrm{O}_{216}\end{array}$ & $\mathrm{Al}_{54} \mathrm{P}_{35.9} \mathrm{Si}_{18.1} \mathrm{O}_{216}$ \\
\hline \multicolumn{3}{|l|}{ Data collection } \\
\hline Wavelength / $\AA$ & 1.54056 & 1.54056 \\
\hline Diffractometer geometry & Debye-Scherrer & Debye-Scherrer \\
\hline Sample & Spinning $1.0 \mathrm{~mm}$ capillary & Spinning $0.7 \mathrm{~mm}$ capillary \\
\hline Scanned region $/ 2 \theta^{\circ}$ & $3.0-80.0$ & $3.0-80.0$ \\
\hline Step size $/ 2 \theta^{\circ}$ & 0.01 & 0.01 \\
\hline \multicolumn{3}{|l|}{ Unit cell } \\
\hline Chemical formula & $\begin{array}{l}{\left[\mathrm{N}_{3.9} \mathrm{C}_{17.5} \mathrm{H}_{34.9}\right]_{3}\left[\mathrm{~N}_{0.9} \mathrm{C}_{2.6} \mathrm{H}_{7.8}\right]_{6}} \\
\mathrm{Al}_{54} \mathrm{P}_{40.5} \mathrm{Si}_{13.5} \mathrm{O}_{216}\end{array}$ & $\mathrm{Al}_{54} \mathrm{P}_{40.5} \mathrm{Si}_{13.5} \mathrm{O}_{216}$ \\
\hline Crystal system & trigonal & trigonal \\
\hline Space group & $R-3$ & $R-3$ \\
\hline$a / \AA$ & $13.64075(31)$ & $13.79540(18)$ \\
\hline$b / \AA$ & $13.64075(31)$ & $13.79540(18)$ \\
\hline$c / \AA$ & $45.4999(13)$ & $44.6461(15)$ \\
\hline Volume / $\AA^{3}$ & 7331.9(4) & $7358.40(24)$ \\
\hline \multicolumn{3}{|l|}{$\mathrm{FWHM}^{\mathrm{a}}$} \\
\hline (009) $/ /^{\circ}$ & 0.230 & 0.286 \\
\hline$(214) / \circ$ & 0.228 & / \\
\hline$(101) / \circ$ & I & 0.232 \\
\hline Refined region $/ 2 \theta^{\circ}$ & $4.0-79.3$ & $4.0-80.0$ \\
\hline Background & Graphically 36 terms & Chebyschev 30 terms \\
\hline$R_{\mathrm{wp}}$ & 0.089 & 0.574 \\
\hline$R_{\mathrm{p}}$ & 0.069 & 0.045 \\
\hline$R_{\mathrm{F}}^{2}$ & 0.129 & 0.049 \\
\hline$X^{2}$ & 3.84 & 2.69 \\
\hline
\end{tabular}

${ }^{a}$ The (009) reflection (more specifically the (001) family) is not affected by possible stacking faults, while (214) and (101) peaks correspond to the major peaks of as-prepared and calcined SAPO-STA-18, respectively. 

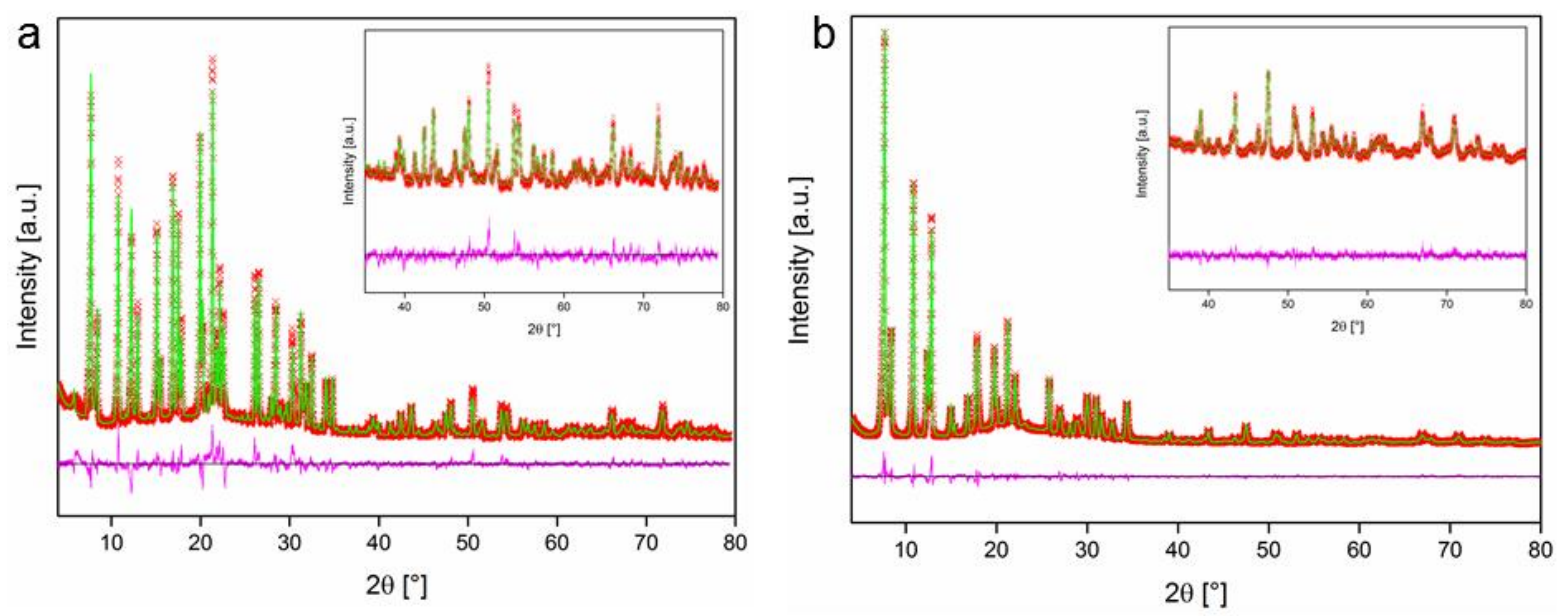

Figure 11. Rietveld plots for (a) as-prepared and (b) calcined SAPO STA-18 synthesised using trimethylamine and diDABCO-C6 as SDAs (observed data (red crosses), calculated fit (green line), and difference plot (purple line)).

\subsection{Co-templating SAPO (GME) (STA-19)}

In contrast to AFX and SFW structures, whose frameworks contain gme and aft or sfw cages, respectively, the stacking sequence of D6Rs in the GME framework generates rows of gme cages and a 12-membered ring channel, both parallel to the $c$-axis. Previously, the zeolitic version of gmelinite has been obtained using quaternary ammonium oligomers of DABCO as structure-directing agents. ${ }^{39}$ Here, the double-template approach was used to prepare a SAPO with the GME topology.

Trimethylamine and quaternary ammonium oligomers of $\mathrm{DABCO}$ with connecting polymethylene chains of different lengths and numbers of repeating units were identified as likely SDAs for gme cages and 12R channels, respectively. Subsequently, DABCO oligomers with $-\mathrm{C}_{5} \mathrm{H}_{10^{-}}$and $-\mathrm{C}_{6} \mathrm{H}_{12^{-}}$connecting chains (i.e. [DABCO-C5] $]_{3}$ and [DABCO-C6 $]_{3}$ ) or with different numbers of repeating units (i.e. $[\mathrm{DABCO}-\mathrm{C} 6]_{3},[\mathrm{DABCO}-\mathrm{C6}]_{5}$ and $[\mathrm{DABCO}-\mathrm{C} 6]_{7}$, (where the subscript represents the average number of repeating units) were used together 
with TrMA in a series of syntheses. TBAOH was employed to raise the $\mathrm{pH}$ to 7 and seeds of AFX, $4 \%$ by weight of the added $\mathrm{SiO}_{2}$, were added to promote the nucleation of SAPO (GME).

Comparing the PXRD patterns of the resulting samples and the simulated diffractogram of the aluminosilicate gmelinite ${ }^{55}$ indicates that with all four oligomers, SAPO (GME) resulted as the main phase (Figure S21). However, minor impurities of SAPO (ATO) and of an unknown phase were detected in the samples prepared with $[\mathrm{DABCO}-6]_{5}$ and $[\mathrm{DABCO}-6]_{7}$, respectively. The crystals of as-prepared SAPO STA-19 are rods 7-8 $\mu \mathrm{m}$ long and $c a .2 \mu \mathrm{m}$ wide (Figure S22). The approximate unit cell composition of SAPO STA-19 prepared with $[\mathrm{DABCO}-\mathrm{C} 6]_{7}$ determined by combined EDX, CHN and TGA corresponds to [[DABCOC6 $\left.]_{7}\right]_{0.9}[\mathrm{TrMA}]_{1.8} \mathrm{Al}_{12} \mathrm{Si}_{3.4} \mathrm{P}_{8.6} \mathrm{O}_{48} \cdot 5 \mathrm{H}_{2} \mathrm{O}$.

To gain insight into the roles played by the TrMA SDA and the SAPO-56 seeds, the synthesis of SAPO (GME) using [DABCO-C6 $]_{3}$ was repeated in their absence. The lack of one or the other component resulted in the formation of SAPO-31 (ATO) either as an impurity or as the only crystalline phase (Figure S23). SAPO-31 is a medium pore material, with 12-membered ring channels (5.4 $\AA$ diameter, narrower than those in SAPO (GME)) running parallel to the $c$-axis. Notably, MgAPO-31 has previously been shown to crystallise in the presence of DABCO-polymethylene polymers. ${ }^{56}$ SAPO-31 does not belong to the ABC-6 family and does not contain gme cages. Both TrMA and SAPO-56 seeds therefore play an important role during the synthesis of SAPO STA-19, by accelerating its nucleation and growth compared to that of SAPO-31. SAPO-56 seeds accelerate nucleation of the GME structure type because it has similar structural layers and the presence of TrMA accelerates the nucleation of gme cages and, together with the oligomers, the growth of the GME topology. In the absence of either, SAPO-31 crystallises, because its narrower channels are a closer fit for the oligomers. 
The four SAPO STA-19 samples were calcined at $550{ }^{\circ} \mathrm{C}$ in dry flowing oxygen to remove the organic SDAs. As Figure S24 shows, SAPO STA-19 prepared with the longer oligomer $[\mathrm{DABCO}-\mathrm{C} 6]_{7}$ is the only material that fully retained the GME topology upon template removal, while the other three materials transform in large part into an AFI-type structure (some SAPO (GME) is still present in the sample synthesised with [DABCO-C6 $]_{3}$ and $\left.[\mathrm{DABCO}-\mathrm{C} 6]_{5}\right)$. Alberti et al. have reported a similar GME $\rightarrow$ AFI transformation for a natural Na-gmelinite zeolite ${ }^{57}$ and have shown that the GME transition occurs via a topotactic 'face-sharing tetrahedra' mechanism. ${ }^{58}$

$\mathrm{N}_{2}$ adsorption on calcined SAPO STA-19 prepared with [DABCO-C6] 7 and SAPO-5 obtained from the topotactic conversion upon calcination of SAPO (GME) prepared with $[\text { DABCO-C6 }]_{3}$, was performed (Figure $\mathrm{S} 25$ ). The $\mathrm{N}_{2}$ uptake at $\mathrm{p} / \mathrm{p}_{0}=0.2$ gave a pore volume of $0.08 \mathrm{~cm}^{3} \mathrm{~g}^{-1}$ for SAPO STA-19 while the $\mathrm{N}_{2}$ uptake for SAPO-5 is negligible, indicating pore blocking of its one-dimensional channels as a result of the transformation.

Solid-state MAS NMR spectra were recorded on dehydrated as-synthesised and calcined samples. The ${ }^{13} \mathrm{C}$ MAS NMR spectrum of SAPO STA-19 was compared with that collected in $\mathrm{D}_{2} \mathrm{O}$ on the pure template $[\mathrm{DABCO}-\mathrm{C} 6]_{7}$ (Figure 12 ). The variation in intensity of the resonances at 54 and $52 \mathrm{ppm}$ suggest that the template undergoes partial fragmentation during the hydrothermal synthesis. The mechanism by which this fragmentation occurs and whether this plays a role in preventing the conversion of GME to AFI will be investigated in future work. The resonance at $47.8 \mathrm{ppm}$ confirms the incorporation of TrMA within the material. The small resonance at $36.9 \mathrm{ppm}$ has been previously assigned to dimethylamine (via trans-methylation). ${ }^{46}$ The ${ }^{27} \mathrm{Al},{ }^{31} \mathrm{P}$ and ${ }^{29} \mathrm{Si}$ MASNMR of as-prepared and calcined samples show similar features to those of SAPO-56 and SAPO (SFW) reported earlier and are given in the caption to Figure S26. 


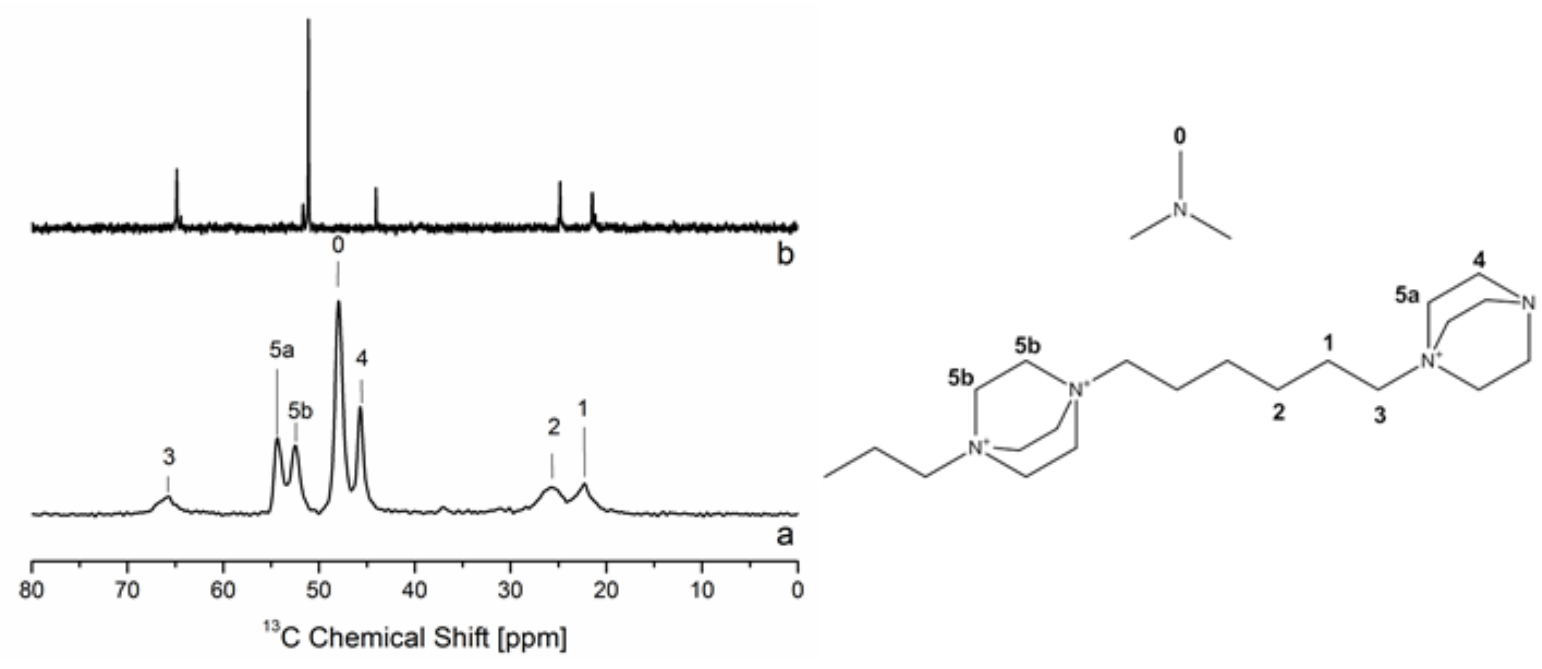

Figure 12. ${ }^{13} \mathrm{C}$ Solid-state MAS NMR spectra of SAPO STA-19 synthesised using trimethylamine and $[\mathrm{DABCO}-\mathrm{C} 6]_{7}$, with suggested peak assignment (a), compared with solution-state ${ }^{13} \mathrm{C}$ NMR of $[\mathrm{DABCO}-\mathrm{C} 6]_{7}$ in $\mathrm{D}_{2} \mathrm{O},(\mathrm{b})$.

The as-prepared structure of SAPO (GME) was not refined because the oligomeric templates are unlikely to be ordered. The structure of calcined, dehydrated SAPO (GME) was refined against X-ray powder diffraction data. The space group was changed from $P 6_{3} / m m c$ (for the silicate) to $P-31 c$ to accommodate $\mathrm{Al}$ and $\mathrm{P}$ alternation within the framework. The refinement with geometric restraints imposed on the bond distances of the atoms in the framework, converged with $R_{F}{ }^{2}=0.062$ and $R_{w p}=0.053\left(\mathrm{R}_{\mathrm{p}}=0.041\right)$, although the relatively low quality of the data resulted in slightly distorted $\mathrm{T}$ site geometries. Attempts to increase the weight of the restraints or the standard deviations of the T-O and O-O distances were not successful. The refined lattice parameters are $a=b=13.8077(5) \AA, c=9.9138(5) \AA$. The refined framework structure of SAPO STA-19 is shown in Figure 13. Crystallographic data are listed in Table 9 while the refinement plot is shown in Figure 14. The final atomic coordinates and thermal parameters are listed in Table S14 while the selected interatomic lengths and angles are summarised in Table S15. 

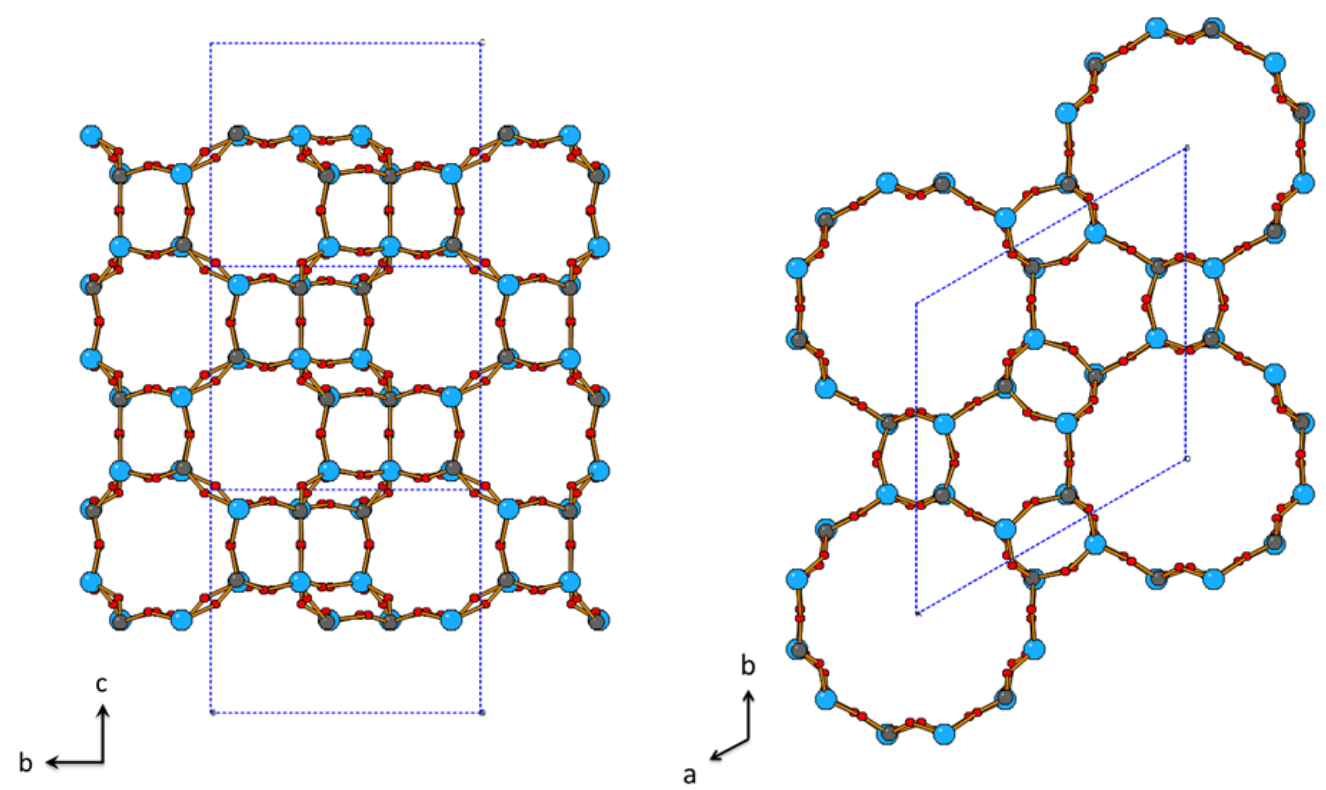

Figure 13. Structure of calcined SAPO (GME), STA-19, viewed perpendicular to (left) and parallel to (right) the $c$ axis, which is the channel axis (light blue: $\mathrm{Al}$, dark gray: $\mathrm{P}$, red: $\mathrm{O}$ ). 
Table 9. Crystallographic data for calcined dehydrated SAPO STA-19 synthesised using trimethylamine and $[\mathrm{DABCO}-\mathrm{C} 6]_{7}$ oligomer as SDAs.

\begin{tabular}{|c|c|}
\hline & $\begin{array}{l}\text { SAPO STA-19 calcined, } \\
\text { dehydrated }\end{array}$ \\
\hline Chemical composition & $\mathrm{Al}_{12} \mathrm{Si}_{3.4} \mathrm{P}_{8.6} \mathrm{O}_{48}$ \\
\hline \multicolumn{2}{|l|}{ Data collection } \\
\hline Wavelength / A & 1.54056 \\
\hline Diffractometer geometry & Debye-Scherrer \\
\hline Sample & Spinning $0.7 \mathrm{~mm}$ capillary \\
\hline Scanned region / $2 \theta^{\circ}$ & $3.0-80.0$ \\
\hline Step size $/ 2 \theta^{\circ}$ & 0.01 \\
\hline \multicolumn{2}{|l|}{ Unit cell } \\
\hline Chemical formula & $\mathrm{Al}_{12} \mathrm{Si}_{3.6} \mathrm{P}_{8.4} \mathrm{O}_{48}$ \\
\hline Crystal system & trigonal \\
\hline Space group & $P-31 c$ \\
\hline$a / \AA$ & $13.8077(5)$ \\
\hline$b / \AA$ & $13.8077(5)$ \\
\hline$c / \AA$ & $9.9138(5)$ \\
\hline Volume / $\AA^{3}$ & $1636.86(15)$ \\
\hline \multicolumn{2}{|l|}{ FWHM $^{\mathrm{a}}$} \\
\hline$(002) /^{\circ}$ & 0.358 \\
\hline$(100) / \circ$ & 0.286 \\
\hline \multicolumn{2}{|l|}{ Rietveld refinement } \\
\hline Refined region / $2 \theta^{\circ}$ & $4.5-80$ \\
\hline Excluded regions $/ 2 \theta^{\circ}$ & $13.17-13.55$ \\
\hline Background & Chebyschev 26 terms \\
\hline$R_{\mathrm{wp}}$ & 0.053 \\
\hline$R_{\mathrm{p}}$ & 0.041 \\
\hline$R_{\mathrm{F}}^{2}$ & 0.062 \\
\hline$X^{2}$ & 1.99 \\
\hline
\end{tabular}

${ }^{a}$ The (002) peak (or more specifically the (001) family) is not affected by possible stacking faults while the (100) peak is the most intense peak of calcined SAPO STA-19. 


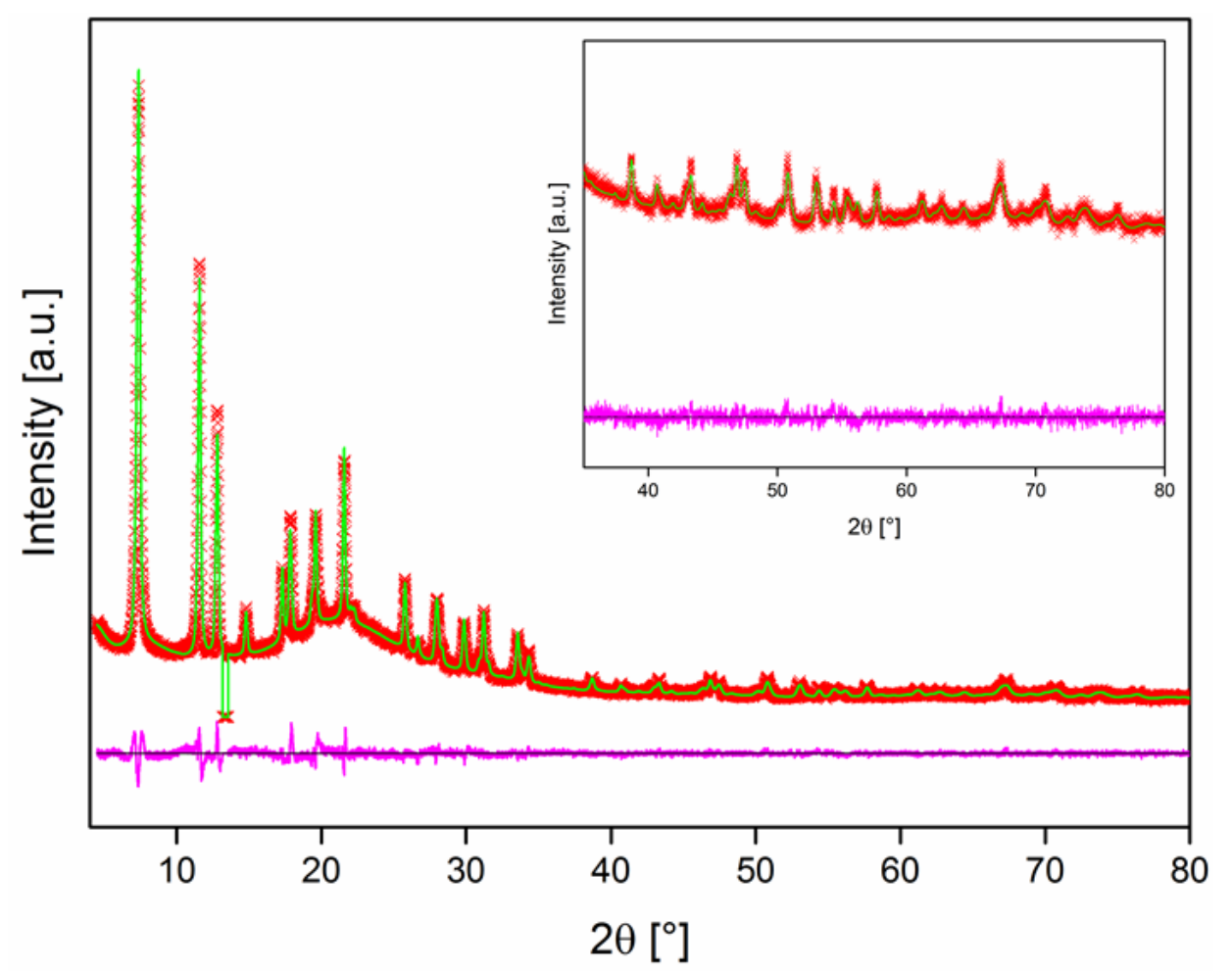

Figure 14. Rietveld plot of calcined SAPO STA-19 synthesised using trimethylamine and [DABCOC6 $]_{7}$ oligomer (observed data (red crosses), calculated fit (green line), and difference plot (purple line)).

\subsection{Discussion}

The use of molecular modelling to identify potential structure directing agents for a given target zeolite structure is a powerful synthetic approach. The additional inclusion of modelling algorithms to select SDAs according to the ease of their synthesis is a valuable addition. Recent examples of this methodology have included the successful synthesis of zeolites with the RTH, STW, AEI and SFW framework topology types. ${ }^{24-27,54}$

Here, the synthesis of three structures with topology types belonging to the ABC- 6 family, as SAPOs, has been achieved via a double template approach. This is a significant extension to the designed synthesis method because small-pore SAPOs have potential applications in adsorption and catalysis. Previously, we have successfully followed a co-templating route to 
prepare small pore SAPOs with the SAV and KFI topology. These zeotypes possess attractive catalytic properties, ${ }^{59}$ but the cost of the azamacrocycles and azacryptand used as SDAs for these D6R zeotypes mitigates against their commercial application, whereas the bisdiazabicycloalkane cations used in the syntheses reported here are readily and economically prepared.

The co-templating method is applicable to the synthesis of frameworks that contain more than one kind of cage or channel which can be templated by a suitably chosen SDA. For aluminosilicate zeolites these can be metal cations as well as organic species. The PAU/MTV/PST-20 family of embedded isoreticular zeolites ${ }^{60}$ are a recent example where a mixture of inorganic $\left(\mathrm{Na}, \mathrm{K}^{+}, \mathrm{Sr}^{2+}\right)$ and organic $\left(\mathrm{TEA}^{+}\right)$cations template the combination of cages required for a particular structure to form. For SAPOs, organic SDAs are strongly favoured due to the tendency for metal cations to precipitate dense phosphates.

A true retrosynthetic approach requires a strong specificity of a certain SDA for a given cage or channel. Although not fully selective, we have shown here that TrMA is effective for gme cages (as well as gis and sod) and that elongated 12R-bounded cages and channels readily crystallise around bisDABCO-alkane cations and oligomers. Furthermore, computational modelling has been shown to be highly effective in assessing this selectivity and so plays an important role: the change in crystallisation selectivity from SAPO-56 (with the aft cage) to SAPO (SFW) (with the $s f w$ cage) occurs as the length of the polymethylene chain between DABCO units is varied between $\mathrm{C} 4, \mathrm{C} 5$ and $\mathrm{C} 6, \mathrm{C} 7, \mathrm{C} 8$, as predicted (Table 8). Further, the poorer fit of diDABCO-C 8 within the $s f w$ cage (expressed by the high torsion energy) results experimentally in the presence of amorphous material within the sample in addition to SAPO $(\mathrm{SFW})$. 
It is also to be expected that the specificity of a combination of SDAs towards a zeotype containing more than one cage or channel will be higher than if a single SDA were used. For example, whereas a range of SDAs give SAPO-56, the selectivity to SAPO-56 under the conditions reported here is strongly favoured by the presence of co-templates. Also in this work, whereas an oligomer might template ATO, AFI or GME framework types, the added TrMA makes the selectivity to GME much greater by stabilising the gme cages that are only found in the GME structure type. The same is true for STA-18 (SFW), where the specificity to the structure comes from the dual templates.

The co-templating method also requires that both SDAs are involved simultaneously in the crystallisation, so they should have a similar templating 'power', which will be a function of both the strength of their interaction with the crystallising structure and their concentration in the gel. In this work, for example, the relative concentration of TrMA must be reduced in some syntheses to avoid competing crystallisation of SAPO-43 (GIS) or SAPO-20 (SOD) and to allow the collaboration of TrMA and the bisDABCOalkane templates. To permit this, an additional organic base is used to adjust the $\mathrm{pH}$ to a value suitable for SAPO crystallisation, that does not show strong structure directing effects. TBAOH is used for this purpose.

Other synthetic parameters can play an important and even a controlling role in dual templating preparations. In this work the addition of seed crystals of SAPO-56 strongly favours the growth of SAPOs that also belong to the ABC- 6 family. ${ }^{61}$ The seeds accelerate the crystallisation of SAPO-56 and SAPO (SFW) at the expense of other phases not belonging to the ABC-6 family, such as SAPO-5. Notably, the action of seed crystals to assist in the crystallisation of zeolites with similar structural units to those of the seeds is of increasing interest, because it opens up the possibility to obtain certain desirable frameworks even without organic SDAs. ${ }^{62-64}$ Additionally, the gel composition and particularly the level of $\mathrm{Si}$ in the gel has an important role. If Si substitutes for P (as observed to some extent for all 
SAPOs here) a negative charge is imparted to the framework that can balance the positive charge of the included quaternary alkylammonium cations. This explains the specific compositional range for pure SAPOs with these cations. Other charge balancing mechanisms are possible (such as the coordination of hydroxyl groups at Al) but these are often highly structure specific. Notwithstanding these additional considerations, the dual template method has been shown to be an effective route to the three SAPOs in the ABC- 6 system described here, even though the way in which trimethylamine and diDABCO act cooperatively is not yet fully understood.

The resulting SAPO materials have been fully characterised once calcined. SAPO-56 and SAPO (SFW) straightforwardly lose SDA and framework-bound hydroxyl groups to give fully tetrahedrally-coordinated microporous frameworks with the connectivity of their parent structures. Some of the samples of SAPO (GME) become tetrahedrally-coordinated SAPO (GME) while others transform topotactically to SAPO-5. This thermodynamically-favoured solid-solid transformation is likely to occur through $\mathrm{H}_{2} \mathrm{O}$-catalysed tetrahedral rearrangements nucleated at defects, the abundance of which will depend on the crystallisation history.

\section{Conclusion}

A retrosynthetic method has been developed to design the synthesis of target silicoaluminophosphates (SAPOs) whose framework belongs to the ABC-6 family and has at least one gme cage per unit cell. This strategy allowed the preparation of SAPO versions of AFX (SAPO-56), SFW (STA-18) and GME (STA-19) types of framework. The method enables the use of two structure-directing agents (SDAs) simultaneously to promote the formation of structure features such as cages or channels of the target framework type. In this 
regard molecular modelling is a powerful tool to discriminate between different SDAs and so identify those with the most favourable energies for a selected cage. Moreover, in this way, SDAs can be selected with a reduced tendency to template cages with size and shape similar to those of the target cage.

The SAPOs described above were synthesised using trimethylamine (or more likely its protonated form) as an SDA for the gme cage and bisDABCO cations or quaternary ammonium oligomers of DABCO with connecting polymethylene chains containing 4-8 methylene units as SDAs for the second type of cage (i.e. aft and $s f w$ ) or the 12R channel, respectively. The ratio between TrMA and the second SDA, the Si/Al ratio, the use of $\mathrm{TBAOH}$ as a $\mathrm{pH}$ modifier and the addition of seeds belonging to the ABC- 6 family are important available synthetic variables to enable improvement in the purity of the target frameworks.

The SAPO materials prepared here have been fully characterised in their as-prepared and calcined forms. The incorporation and location of the SDAs were achieved by combining ${ }^{13} \mathrm{C}$ MAS NMR, molecular modelling and Rietveld refinement on PXRD data and trimethylamine species were in all cases located within the gme cages. ${ }^{27} \mathrm{Al},{ }^{31} \mathrm{P}$ and ${ }^{29} \mathrm{Si}$ MAS NMR spectra of the as-prepared and calcined SAPO-56, STA-18 and STA-19 samples indicate that Si mainly replaces $\mathrm{P}$ in the as-prepared frameworks, resulting in negatively-charged frameworks.

The 'double template' method opens up the possibility of synthesising other materials possessing two different cage types, both of a known topology type but with an unprecedented composition or with topology types as yet only predicted hypothetically. On a more fundamental level, the cooperative way in which the two SDAs act during nucleation 
and crystal growth should be studied in depth to enable the full potential of the method to be realised.

\section{ASSOCIATED CONTENT}

\section{Supporting Information}

The Supporting Information is available free of charge on the ACS Publications website at DOI:

Details of sample preparation, crystallography, adsorption isotherms, NMR spectra and additional figures/tables. The research data (and materials) supporting this publication can be accessed at DOI http://dx.doi.org/10.17630/c15f1858-5059-4818-ba8a-922d4aeea078.

\section{AUTHOR INFORMATION}

\section{Corresponding Authors}

* P. A. Wright paw2@st-andrews.ac.uk and A. Turrina alessandro.turrina@ matthey.com

\section{ACKNOWLEDGEMENTS}

This work has been supported by Johnson Matthey PLC, UK. Solid-state NMR spectra were obtained at the EPSRC UK National Solid-state NMR Service at Durham. We thank Mrs. Sylvia Williamson (St Andrews) for collection of TGA, AAS and $\mathrm{N}_{2}$ adsorption isotherms and Mr. Stephen Boyer (London Metropolitan University) for Elemental Analysis. 


\section{REFERENCES}

1. First, E. L.; Hasan, M. M. F.; Floudas, C. A. Discovery of novel zeolites for natural gas purification through combined material screening and process optimization. AlChE J. 2014, $60,1767-1785$.

2. Jae, J.; Tompsett, G. A.; Foster, A. J.; Hammond, K. D.; Auerbach, S. M.; Lobo, R. F.; Huber, G. W. Investigation into the shape selectivity of zeolite catalysts for biomass conversion. J. Catal. 2011, 279, 257-268.

3. Ma, L.; Cheng, Y.; Cavataio, G.; McCabe, R. W.; Fu, L.; Li, J. Characterization of commercial Cu-SSZ-13 and Cu-SAPO-34 catalysts with hydrothermal treatment for $\mathrm{NH}_{3}$ SCR of NOx in diesel exhaust. Chem. Eng. J. 2013, 225, 323-330.

4. Haw, J.; Song, W.; Marcus, D. M. The mechanism of methanol to hydrocarbon catalysis. Acc. Chem. Res. 2003, 36, 317-326.

5. Baerlocher, Ch.; McCusker, L.B.; Olson, D.H. Atlas of Zeolite Framework Types, 6th revised edition, Elsevier, Amsterdam, 2007. http://www.iza-structure.org/databases.

6. Foster, M.D.; Treacy, M.M.J. Atlas of Prospective Zeolite Structures. http://www.hypotheticalzeolites.net/.

7. Deem, M. W. Deem Database. http://www.hypotheticalzeolites.net/DATABASE /DEEM/index.php.

8. Li, Y.; Li, X.; Liu, J.; Duan, F.; Yu, J. In silico prediction and screening of modular crystal structures via a high-throughput genomic approach. Nature Comm. 2015, 6, Art. No. 8328. 
9. Bai, P.; Jeon, M. Y.; Ren, L.; Knight, C.; Deem, M. W.; Tsapatsis, M.; Siepmann, J. I. Discovery of optimal zeolites for challenging separations and chemical transformations using predictive materials modelling. Nature Commun. 2015, 6, Art. No. 5912.

10. Lok, B. M.; Cannan, T. R.; Messina, C. A. The role of organic molecules in molecular sieve synthesis. Zeolites, 1983, 3, 282-291.

11. Shannon, M. D.; Casci, J. L.; Cox, P. A.; Andrews, S. J. Structure of the two-dimensional medium-pore high-silica zeolite NU-87. Nature, 1991, 353, 417-420.

12. Moini, A.; Schmitt, K. D.; Valyocsik, E. W.; Polomski, R. F. The role of diquaternary cations as directing agents in zeolite synthesis. Zeolites, 1994, 14, 504-511.

13. Lobo, R. F.; Zones, S. I.; Davis, M. E. Structure-direction in zeolite synthesis. J. Incl. Phen. Mol. Recog. Chem. 1995, 21, 47-78.

14. Wright, P.A. Microporous Framework Solids, RSC Publishing, 2007.

15. Jackowski, A.; Zones, S. I.; Hwang, S.-J.; Burton, A. W. Diquaternary ammonium compounds in zeolite synthesis: cyclic and polycyclic N-heterocycles connected by methylene chains. J. Am. Chem. Soc. 2009, 131, 1092-1100.

16. Wang, Z.; Yu, J.; Xu, R. Needs and trends in rational synthesis of zeolitic materials. Chem. Soc. Rev. 2012, 41, 1729-1741.

17. Moliner, M.; Rey, F.; Corma, A. Towards the Rational Design of Efficient Organic Structure-Directing Agents for Zeolite Synthesis. Angew. Chem. Int. Ed. 2013, 52, $13880-13889$. 
18. Stevens, A. P.; Gorman, A. H.; Freeman, C. M.; Cox, P. A. Prediction of template location via a combined Monte Carlo-simulated annealing approach. J. Chem. Soc. Farad. Trans. 1996, 92, 2065-2073.

19. Cox, P. A.; Casci, J. L.; Stevens, A. P. Molecular modelling of templated zeolite synthesis. Farad. Discuss., 1997, 106, 473-487.

20. Catlow, C. R. A.; Bell, R. G.; Cora, F.; Slater, B. In Introduction to Zeolite Science and Practice. Stud. Surf. Sci. Catal. 2007, 168, 659-700.

21. Pulido, A.; Moliner, M.; Corma, A. Rigid/Flexible Organic Structure Directing Agents for Directing the Synthesis of Multipore Zeolites: A Computational Approach. J. Phys. Chem. C 2015, 119, 7711-7720.

22. Lewis, D. W.; Willock, D. J.; Catlow, C. R. A.; Thomas, J. M.; Hutchings, G. De novo design of structure-directing agents for the synthesis of microporous solids. Nature, 1996, $382,604-606$.

23. Lewis, D. W.; Sankar, G.; Wyles, J. K.; Thomas, J. M.; Catlow, C. R. A.; Willock, D. J. Synthesis of a Small - Pore Microporous Material Using a Computationally Designed Template. Angew. Chem. Int. Ed. 1997, 36, 2675-2677.

24. Pophale, R.; Daeyart, F.; Deem, M. W. Computational prediction of chemically synthesizable organic structure directing agents for zeolites. J. Mater. Chem. A 2013, 1, $6750-6760$.

25. Schmidt, J. E.; Deimund, M. A.; Davis, M. E. Facile Preparation of Aluminosilicate RTH across a Wide Composition Range Using a New Organic Structure-Directing Agent. Chem. Mater. 2014, 26, 7099-7105. 
26. Schmidt, J. E.; Deem, M. W.; Lew, C.; Davis, T. M. Computationally-guided synthesis of the 8-ring zeolite AEI. Top. Catal. 2015, 58, 410-415.

27. Schmidt, J. E.; Deem, M. W.; Davis, M. E. Synthesis of a Specified, Silica Molecular Sieve by Using Computationally Predicted Organic Structure-Directing Agents. Angew. Chem. Int. Ed. 2014, 126(32), 8512-8514.

28. Wright, P. A.; Jones, R. H.; Natarajan, S.; Bell, R. G.; Chen, J.; Hursthouse, M.; Thomas, J. M. Synthesis and structure of a novel large-pore microporous magnesium-containing aluminophosphate (DAF-1). J. Chem. Soc. Chem. Commun. 1993, 633-635.

29. Gramm, F.; Baerlocher, C.; McCusker, L. B.; Warrender, S. J.; Wright, P. A.; Han, B.; Hong, S. B.; Zheng, L.; Oshuna, T.; Terasaki, O. Complex zeolite structure solved by combining powder diffraction and electron microscopy. Nature, 2006, 444, 79-81.

30. Castro, M.; Garcia, R.; Warrender, S. J.; Wright, P. A.; Cox, P.A.; Fecant, A.; MellotDraznieks C.; Bats, N. Co-templating and modelling in the rational synthesis of zeolitic solids. Chem. Commun. 2007, 3470-3472.

31. Picone, A. L.; Warrender, S. J.; Slawin, A. M. Z.; Dawson, D. M.; Ashbrook, S. E.; Wright, P. A.; Thompson, S. P.; Gaberova, L.; Llewellyn, P. L.; Moulin, B.; Vimont, A.; Daturi, M.; Park, M. B.; Sung, S. K.; Nam I.-S.; Hong, S. B. A co-templating route to the synthesis of Cu SAPO STA-7, giving an active catalyst for the selective catalytic reduction of NO. Microporous Mesoporous Mater. 2011, 146, 36-47.

32. Kirchner, M. T.; Boese, R.; Billups, W. E.; Norman, L. R. Gas hydrate single-crystal structure analysis. J. Am. Chem. Soc. 2004, 126, 9407-9412

33. Gies, H.; van Koningsveld, H. Catalogue of Disorder in Zeolite Frameworks http://www.iza-structure.org/databases/. 
34. Turrina, A.; Eschenroeder, E. C.; Bode, B. E.; Collier, J. E.; Apperley, D. C.; Cox, P. A.; Casci, J. L.; Wright, P. A. Understanding the structure directing action of copper-polyamine complexes in the direct synthesis of Cu-SAPO-34 and Cu-SAPO-18 catalysts for the selective catalytic reduction of $\mathrm{NO}$ with $\mathrm{NH}_{3}$. Microporous Mesoporous Mater. 2015, 215, 154-167.

35. Wilson, S. T.; Broach, R. W.; Blackwell, C. S.; Bateman, C. A.; McGuire, N. K.; Kirchner, R. M. Synthesis, characterization and structure of SAPO-56, a member of the ABC double-six-ring family of materials with stacking sequence AABBCCBB. Microporous Mesoporous Mater. 1999, 28, 125-137.

36. Maple, M. J.; Williams, C. D. Synthesis and characterisation of aluminophosphate-based zeotype materials prepared with $\alpha$, $\omega$-bis ( $\mathrm{N}$-methylpyrrolidinium) alkane cations as structure-directing agents. Dalton Trans. 2007, 4175-4181.

37. Wang, D.; Yang, M.; Zhang, W.; Fan, D.; Tian, P.; Liu, Z. Hollow nanocrystals of silicoaluminophosphate molecular sieves synthesized by an aminothermal co-templating strategy. CrystEngComm. 2016, 18, 1000-1008.

38. Xie, D.; McCusker, L. B.; Baerlocher, C.; Zones, S. I.; Wan, W.; Zou, X. SSZ-52, a zeolite with an 18-layer aluminosilicate framework structure related to that of the DeNOx catalyst Cu-SSZ-13. J. Am. Chem. Soc. 2013, 135, 10519-10524.

39. Daniels, R. H.; Kerr, G. T.; Rollmann, L. D. Cationic polymers as templates in zeolite crystallization. J. Am. Chem. Soc. 1978, 100, 3097-3100.

40. Materials Studio version 6.1, Accelrys Inc., San Diego, USA, 2012.

41. (a) Rietveld, H. M. A profile refinement method for nuclear and magnetic structures. $J$. Appl. Crystallogr. 1969, 2, 65-71. (b) Larson, A.; Dreele, R. B. von General Structure Analysis System GSAS, Los Alamos National Laboratory, Los Alamos, NM, 2000. (c) Toby, 
B. H. EXPGUI, a graphical user interface for GSAS. J. Appl. Crystallogr. 2001, 34, 210-213.

42. Hastings, J. B.; Thomlinson, W.; Cox, D. E. Synchrotron X-ray powder diffraction. $J$. Appl. Crystallogr. 1984, 17, 85-95.

43. Camblor, M.A.; Diaz-Cabanas, M.-J.; Cox, P. A.; Shannon, I. J.; Wright, P. A.; Morris, R. E. A synthesis, MAS NMR, synchrotron X-ray powder diffraction and computational study of zeolite SSZ-23. Chem. Mater., 1999, 11, 2878-2885

44. Luz, Z.; Meiboom, S. Nuclear magnetic resonance study of the protolysis of trimethylammonium ion in aqueous solution-order of the reaction with respect to solvent. $J$. Chem. Phys. 1963, 39, 366-370.

45. Thursfield, A.; Anderson, M. W.; Dwyer, J.; Hutchings, G. J.; Lee, D. ${ }^{13} \mathrm{C}$ and ${ }^{15} \mathrm{~N}$ solidstate MAS NMR study of the conversion of methanol and ammonia over H-RHO and HSAPO-34 microporous catalysts J. Chem. Soc., Faraday Trans. 1998, 94, 1119-1122.

46. Ernst, H.; Pfeifer, H. Synthesis of methylamines studied by in situ carbon-13 MAS NMR spectroscopy. J. Catal. 1992, 136, 202-208.

47. Jiang, Y.; Huang, J.; Wang, W.; Hunger, M. Formation of methylamines by the reaction of ammonia with surface methoxy species on zeolite HY and the silicoaluminophosphate HSAPO-34. Stud. Surf. Sci. Catal. 2007, 170, 1331-337.

48. Castro, M.; Seymour, V. R.; Carnevale, D.; Griffin, J. M.; Ashbrook, S. E.; Wright, P. A.; Apperley, D. C.; Parker, J. E.; Thompson, S. P.; Fecant, A.; Bats, N. Molecular modeling, multinuclear NMR, and diffraction studies in the templated synthesis and characterization of the aluminophosphate molecular sieve STA-2. J. Phys. Chem. C 2010, 114, 12698-12710. 
49. Alkorta, I.; Elguero, J. A GIAO/DFT study of ${ }^{1} \mathrm{H},{ }^{13} \mathrm{C}$ and ${ }^{15} \mathrm{~N}$ shieldings in amines and its relevance in conformational analysis. Magn. Reson. Chem. 2004, 42, 955-961. ACD: Spectral data were obtained from Advanced Chemistry Development, Inc.

50. (a) Davis, M. E.; Lobo, R. F. Zeolite and molecular sieve synthesis. Chem. Mater. 1992, 4, 756-768. (b) Lobo, R. F.; Zones, S. I.; Davis, M. E. Structure-direction in zeolite synthesis. J. Inclus. Phenom. 1995, 21, 47-78. (c) Lobo, R. F. Synthesis and Rietveld refinement of the small-pore zeolite SSZ-16. Chem. Mater. 1996, 8, 2409-2411.

51. Jiang, F. Y.; Tang, Z. K.; Zhai, J. P.; Ye, J. T.; Han, J. R. Synthesis of $\mathrm{AlPO}_{4}-5$ crystals using TBAOH as template. Microporous Mesoporous Mater. 2006, 92, 129-133.

52. Strohmaier, K.; Vaughan D. U.S. Patent Application 10/348, 363, 2003.

53. Jeon, H.-Y.; Shin, C.-H.; Jung, H. J.; Hong, S. B. Catalytic evaluation of small-pore molecular sieves with different framework topologies for the synthesis of methylamines. Appl. Catal. A 2006, 305, 70-78.

54. Davis, T.M; Liu, A. T.; Lew, C. M.; Xie, D.; Benin, A. I.; Elomari, S.; Zones, S. I.; Deem, M. W. Computationally-Guided Synthesis of SSZ-52, a Zeolite for Engine Exhaust Clean-up Chem. Mater., 2016, 28, 708-711.

55. Fischer, K. Untersuchung der Kristallstruktur von Gmelinit N. Jb. Miner. Mh., 1966, 113.

56. Wright, P.A.; Cox, P. A.; Noble, G. W.; Patinec, V. Experimental and computational studies of magnesioaluminophosphates synthesised using polymeric and oligomeric templates. Proc. 12th Intl. Zeolite Conference, Baltimore, 1998, Materials Res. Soc, Warrendale, 1999, 1603-1610. 
57. Alberti, A.; Parodi, I.; Cruciani, G.; Dalconi, M. C.; Martucci, A. Dehydration and rehydration processes in gmelinite: An in situ X-ray single-crystal study. Amer. Mineral. 2010, 95, 1773-1782.

58. Alberti, A.; Martucci, A. Reconstructive phase transitions in microporous materials: Rules and factors affecting them. Microporous Mesoporous Mater. 2011, 141, 192-198.

59. Castro, M.; Warrender, S.; Wright, P. A.; Apperley, D. C.; Belmabkhout, Y.; Pirngruber, G.; Park, M. B.; Min, H.-K.; Hong, S. B. Silicoaluminophosphate molecular sieves STA-7 and STA-14 and their structure-dependent catalytic performance in the conversion of methanol to olefins J. Phys. Chem. C 2009, 113, 15731-15741.

60. Guo, P.; Shin, J.; Greenaway, A. G.; Min, J. G.; Su, J.; Choi, H. J.; Liu, L.; Cox, P. A.; Hong, S. B.; Wright, P. A.; Zou, X. A zeolite family with expanding structural complexity and embedded isoreticular structures Nature 2015, 524, 74-78.

61. Anwar, J.; Khan, S.; Lindfors, L. Secondary Crystal Nucleation: Nuclei Breeding Factory Uncovered Angew. Chem. Int. Ed. 2015, 54, 14681-14684.

62. Wu, Z. F.; Song, J. W.; Ji, Y. Y.; Ren, L. M.; Xiao, F.-S. Organic template-free synthesis of ZSM-34 zeolite from an assistance of zeolite L seeds solution. Chem. Mater. 2008, 20, $357-359$

63. Kamimura, Y.; Itabashi, K.; Okubo, T. Seed-assisted, OSDA-free synthesis of MTW-type zeolite and "Green MTW" from sodium aluminosilicate gel systems Microporous Mesoporous Mater. 2012, 147, 149-156.

64. Wu, Q.; Wang, X.; Qi, G.; Guo, Q.; Pan, S.; Meng, Y.; Xu, J.; Deng, F.; Fan, F.; Li, C.; Maurer, S.; Müller, U.; Xiao, F.-S. Sustainable synthesis of zeolites without addition of both organotemplates and solvents. J. Am. Chem. Soc. 2014, 136, 4019-4025. 